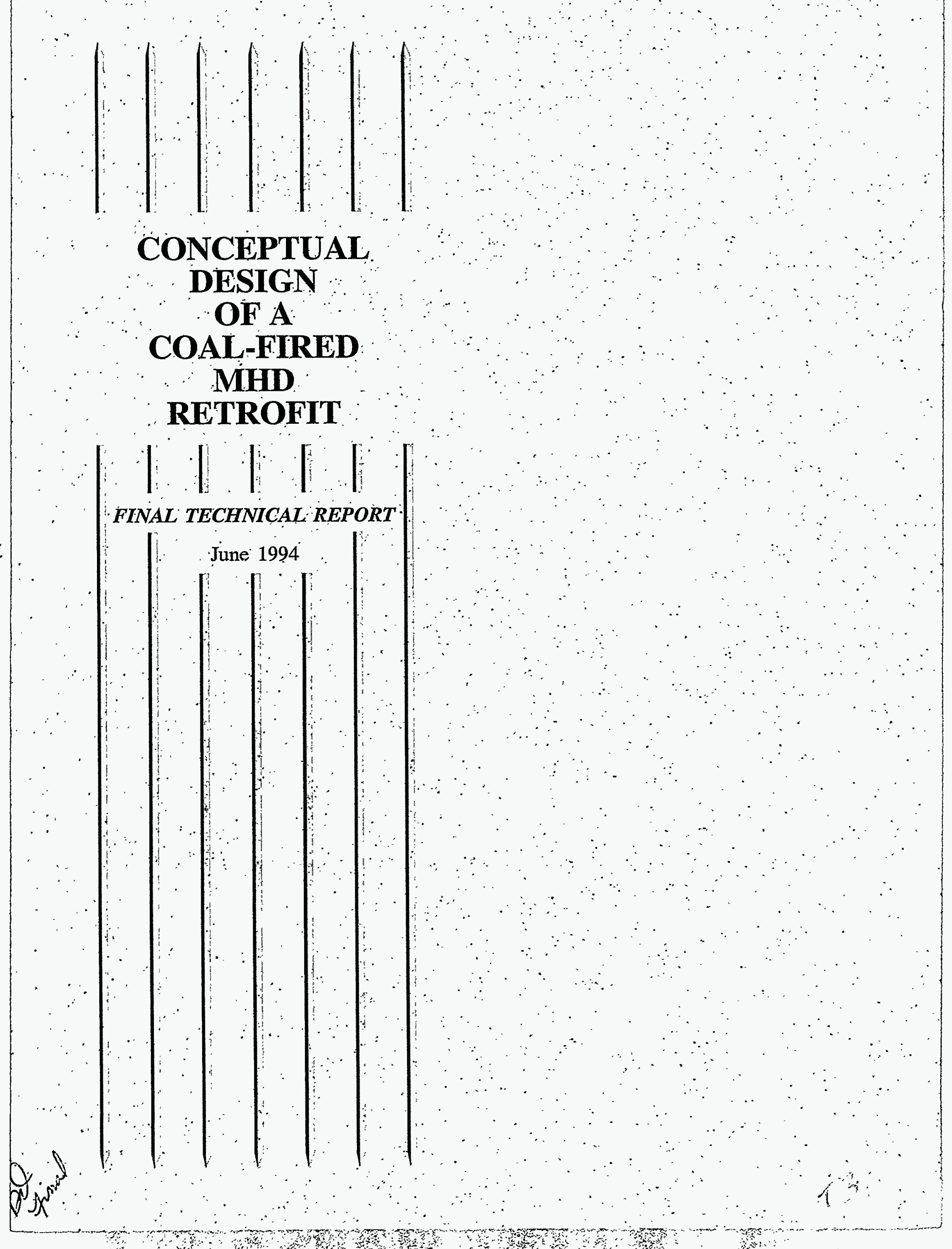




\section{CONCEPTUAL DESIGN OF A COAL-FIRED MHD RETROFIT}

\section{FINAL TECHNICAL REPORT}

Prepared by

MHD Development Corporation for the U.S. Department of Energy Pittsburgh Energy Technology Center under contract DE-AC22-87PC79669
Point of Contact

(For further information or additional copies)

Mr. Robert J. Labrie, President MHD Development Corporation P.O. Box 3809 Butte, MT 59702 (406) $782-0463$
We have no objection from a patent standpoint to the publication or dissemination of this material.

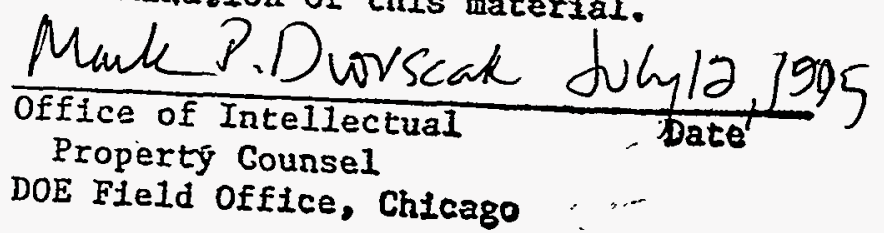

\section{DISCLAIMER}

This report was prepared as an account of work sponsored by an agency of the United States Government. Neither the United States Government nor any agency thereof, nor any of their employees, makes any warranty, express or implied, or assumes any legal liability or responsibility for the accuracy, completeness, or usefulness of any information, apparatus, product, or process disclosed, or represents that its use would not infringe privately owned rights. Reference herein to any specific commercial product, process, or service by trade name, trademark, manufacturer, or otherwise does not necessarily constitute or imply its endorsement, recommendation, or favoring by the United States Government or any agency thereof. The views and opinions of authors expressed herein do not necessarily state or reflect those of the United States Government or any agency thereof.

This report was prepared as an account of work sponsored by an agency of the United States Government. Neither the United States nor any agency thereof, nor any of their employees, makes any warranty, expressed or implied, or assumes any legal liability or responsibility for any third party's use or the results of such use of any information, apparatus, product, or process disclosed in this report, or represents that its use by such third party would not infringe privately owned rights. 


\section{DISCLAIMER}

Portions of this document may be illegible in electronic image products. Images are produced from the best available original document. 


\section{CONTENTS}

Section 1 Introduction $\ldots \ldots \ldots \ldots \ldots \ldots \ldots$

Section 2 MHD . . . . . . . . . . . 3

Section 3 Summary of Development (Proof-of-Concept) $\ldots 5$

Section 4 Integrated Demonstration Design Modifications $\ldots 9$

Section 5 Remaining Open Items $\ldots \ldots \ldots \ldots \ldots 25$

Section 6 Perspective on Government and Industrial Technology Development . . . . . . . . . . 27

Section 7 Options for the Future of MHD . . . . . . . 31

Section 8 Conclusion $\ldots \ldots \ldots \ldots \ldots \ldots \ldots$

Appendix A Glossary $\ldots \ldots \ldots \ldots \ldots \ldots \ldots$ 


\section{ACRONYMS}

BMDP Billings MHD Demonstration Project

CDIF Component Development and Integration Facility

CFFF Coal Fired Flow Facility

DOE U.S. Department of Energy

EPRI Electric Power Research Institute

HRSR heat recovery/seed recovery

MDC MHD Development Corporation

MHD magnetohydrodynamics

NSPS New Source Performance Standards

PETC Pittsburgh Energy Technology Center

POC Proof-of-Concept

SCMS superconducting magnet system 


\section{INTRODUCTION}

Coal-fired magnetohydrodynamics (MHD) technology is ready for its next level of development-an integrated demonstration at a commercial scale. The development and testing of MHD has shown its potential to be the most efficient, least costly, and cleanest way to burn coal. Test results have verified a greater than $99 \%$ removal of sulphur with a potential for greater than $60 \%$ efficiency. This development and testing, primarily funded by the U.S. Department of Energy (DOE), has progressed through the completion of its proof-of-concept (POC) phase at the $50 \mathrm{MWt}$ Component Development and Integration Facility (CDIF) and $28 \mathrm{MWt}$ Coal Fired Flow Facility (CFFF), thereby, providing the basis for demonstration and further commercial development and application of the technology. The conceptual design of a retrofit coal-fired MHD generating plant was originally completed by the MHD Development Corporation (MDC) under this Contract, DE-AC22-87PC79669. Thereafter, this concept was updated and changed to a stand-alone MHD demonstration facility and submitted by MDC to DOE in response to the fifth round of solicitations for Clean Coal Technology. Although not selected, that activity represents the major interest in commercialization by the developing industry and the type of demonstration that would be eventually necessary. This report updates the original executive summary of the conceptual design by incorporating the results of the POC program as well as MDC's proposed Billings MHD Demonstration Project (BMDP) and outlines the steps necessary for commercialization. 


\section{MHD}

MHD electrical power generation is achieved by burning coal in a pressurized combustor with preheated air or oxygen to produce a combustion gas having a temperature between 4,700 and $5,000{ }^{\circ} \mathrm{F}$. A seed material, such as a potassium salt, is added to increase electrical conductivity. This combustion gas and vaporized/ionized seed are passed through a duct or channel surrounded by a superconducting magnet to produce direct current electrical power. The remaining heat is used to make steam to drive a conventional turbine generator. Appendix A contains a glossary of terms used in MHD technology and throughout this report.

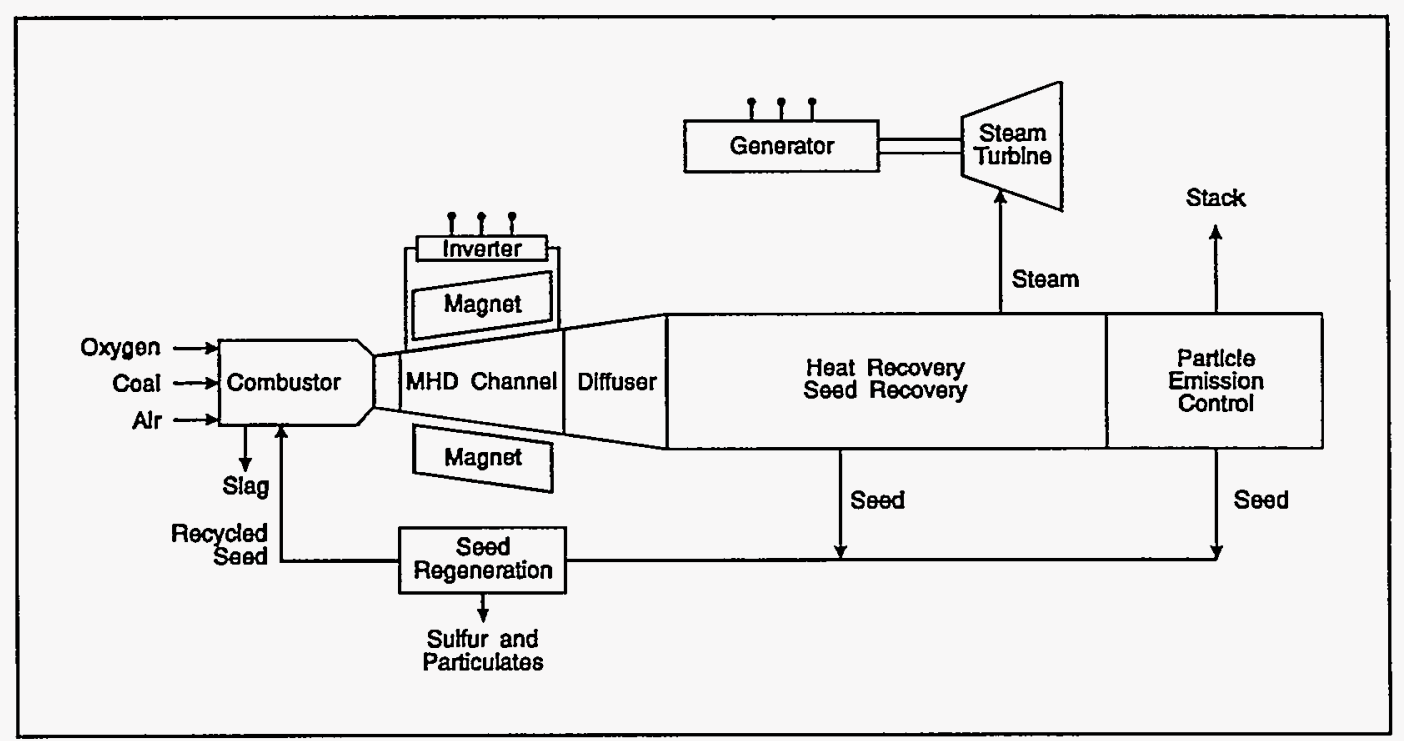

Figure 1. Open Cycle MHD System Component Arrangement 
Section 2

In addition to the potential for large efficiency increases, MHD also greatly reduces emissions. Sulphur emissions are essentially eliminated when the seed material combines with the sulfur oxides to make potassium sulfate. Both the fly ash and the potassium sulfate are recovered as solids; therefore, sulfur oxides are eliminated. Tests have shown that the nitrous oxide emissions would be about one-sixth of today's standards, and particulate emissions can be reduced using conventional baghouse or electrostatic precipitator technologies. Because of the higher efficiency, MHD plants would also reduce carbon dioxide to about $60 \%$ of today's emissions. 


\section{SUMMARY OF DEVELOPMENT (PROOF-OF-CONCEPT)}

DOE has supported MHD research and development for the past three decades with the intent of building an adequate engineering data base to support commercialization. The U.S. Government and the private sector have invested ${ }^{1}$ more than $\$ 850$ million in research and development during that period of time.

The MHD effort in the 1960s and 1970s was focused on developing and testing individual MHD components at several small laboratory-size test facilities. In the early 1980s, DOE began developing and testing MHD components at two test facilities that were constructed in the late 1970s. These facilities are owned by DOE, operated by private contractors, and contain some equipment built with private (nonfederal) funds. The $50 \mathrm{MWt}$ CDIF is located in Butte, Montana, and the $28 \mathrm{MWt}$ CFFF is located in Tullahoma, Tennessee.

In 1984, DOE held public meetings to discuss the direction of MHD research and to formulate a more focused approach to its MHD program. The MHD POC program was established as a result of a consensus between government and industry representatives participating in these meetings. DOE formulated its detailed plans and objectives for the POC program during the next 3 years and awarded the first contracts under the POC program in September 1987. The POC program has been managed by DOE's Pittsburgh Energy Technology Center (PETC).

The MHD POC program was established as a result of a consensus between government and industry representatives.

${ }^{1}$ The July 1993 GAO report to Congress on the MHD Development Program. 


\section{Section 3}

The purpose of the POC program was to develop the technology base necessary for the private sector to pursue further development and application of MHD technology at new or existing commercial power plants.
The purpose of the POC program was to develop the technology base necessary for the private sector to pursue further development and application of MHD technology at new or existing commercial power plants. The main objectives of the POC program were to test and demonstrate the POC of (1) the integrated topping cycle system at the CDIF; (2) the integrated bottoming cycle system at the CFFF; and (3) the potassium seed regeneration system at a TRW facility in California. This regeneration system is intended to economically convert the spent potassium seed recovered from the bottoming cycle to a sulfur-free potassium compound that can be reused in the combustor. In addition, the POC program was to study the feasibility of retrofitting MHD power systems to existing coal-fired plants. The retrofit studies were done by separate teams of contractors on commercial power plants in Florida and Montana.

The POC program was officially concluded on September 30, 1993. Not all of the planned topping and bottoming cycle tests were completed, but budget decisions required the conclusion of the program at that time.

These accomplishments verify that the development program provides the engineering data base that would allow the design of the first large-scale integrated MHD plant design.

An industrial proposal to build such an MHD plant was submitted to DOE as part of the Clean Coal Technology V solicitation. Although it was not successful, it was nonetheless a significant landmark for MHD. It represented the first commercial proposal for an MHD power plant and was tendered by a credible team with excellent credentials to actually build such a plant. This is a clear beginning of commercial interest in developing MHD technology.

DOE evaluators gave higher priority to other nearer-term clean coal technologies, and this first-of-a-kind MHD plant was not selected due to solicitation criteria basis. A key observation of the selection committee was that nothing was found to detract from or lessen the potential of MHD as a technology. It just appears to be too far out to compete with those technologies presently ready for commercialization. MHD may not fit within the intent of the clean coal programs. 


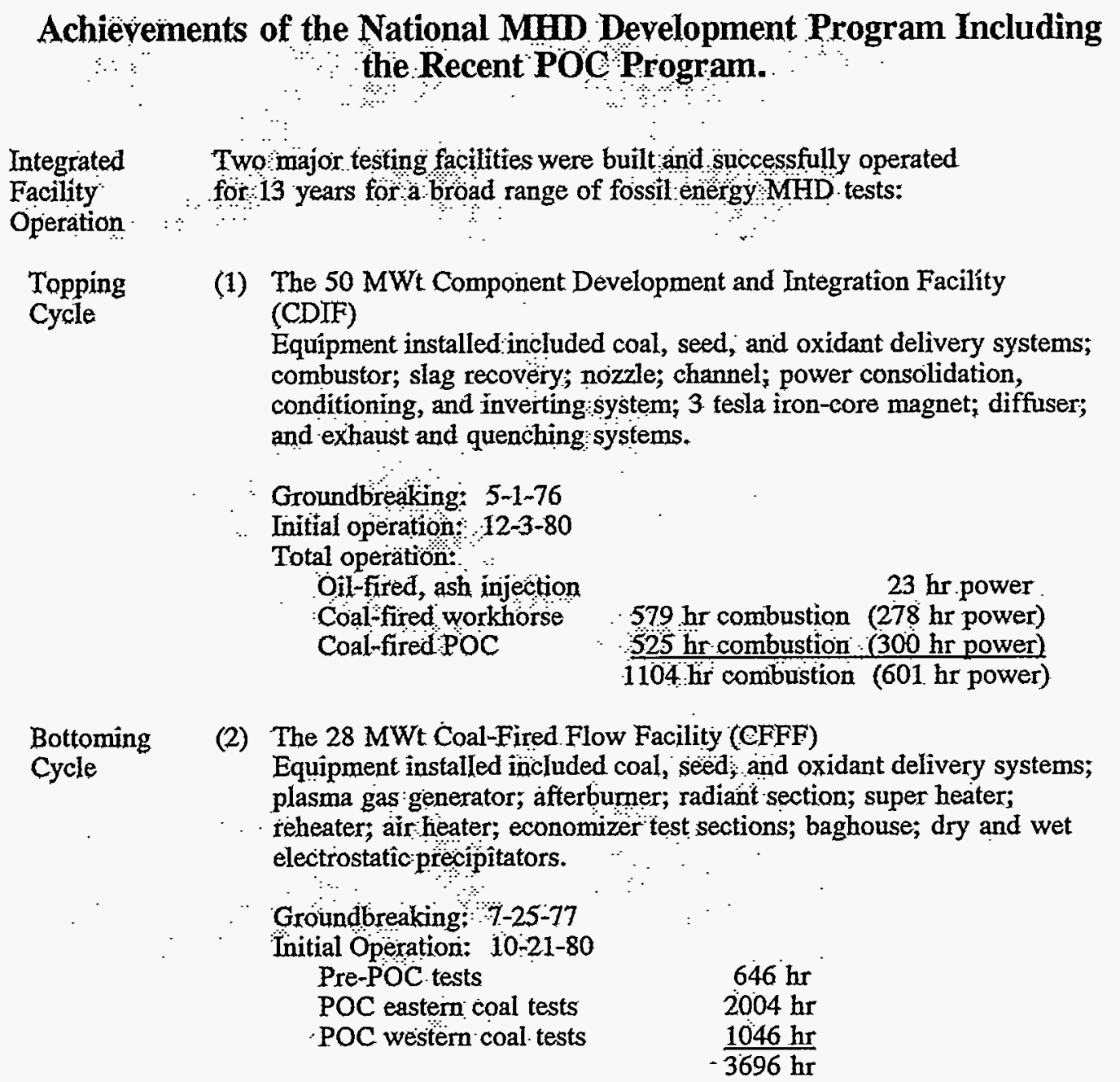

Environmental Consistently demonstrated sulfur oxides removal of $>98 \%$ and particulate removal at 173 New Source Performance Standard Limit (for all coals tested); nitrogen oxides production at $\sim 0.1 \mathrm{lb} / \mathrm{mBtu}$ (Eastern coal), $0.15 \mathrm{lb} / \mathrm{mBtu}$ (Western coal); organic pollutants at less than detectable levels, attributed to the extremely high combustion temperatures; levels of inorganic pollutants comparable to other coal-fired processes, however, the higher efficiency of commercial MHD. will result: in significantly less of these pollutants per megawatt of electrîncity produced; similarly, the emission of carbon dioxide is projected to be substantially less than other combustion processes.

High Power Short-term electric power generation in the High Performance at $290 \mathrm{MWt}$ Demonstration Performance. Experiment achieved predicted performance verifying enthalpy extraction projections. Tests were performed at the Arnold Engineering Development Center near Tullahoma, Tennessee. 


\section{Section 3}

\section{Achievements of the National MHD Development Program Including the Recent POC Program (con't).}

Integrated
Demonstration

Channel

Combustor

Magnet

Inverter

Heat Recovery/

Seed Recovery

Seed Regeneration
Conceptual retrofit design studies have been completed and a standalone conceptual integrated demonstration design was the basis for the proposal submitted to Clean Coal Technology V.

1,300 hours of MHD electrical generator tests (independent of the CDIF tests) were completed and 8,000-hour electrode lifetimes were projected by Textron Defense Systems/Avco Research at Everett, Massachusetts. The POC channel was successfully tested at the CDIF for over 500 hours, and new sidewall designs were tested at CFFF. Confidence has been established for material selection for channel electrodes and channel changeout capability to meet the lifetime requirements of the first commercial demonstration plant.

10-, 20-, and 50-MWt coal slagging combustors were built and tested by TRW Space and Technology Group in Redondo Beach, California. Confidence has been established for scalability and durability with design life capable of meeting the lifetime requirements of the commercial demonstration plant. A nonslagging combustor was tested and operated at the CFFF in Tennessee throughout the $\sim 3,350$ hours of POC testing.

Early MHD tests established the first sustained operation of a superconducting magnet. A superconducting magnet was built in the United States and has been operated in the (former) Soviet Union as part of a joint co-op program. A 6.0 tesla superconducting magnet was built, tested, and operated at the Argonne National Lab.

A 3.5 MWe inverter in operation at the CDIF was designed by the Electric Power Research Institute (EPRI) in Palo Alto, California, and built by Westinghouse in Pittsburgh, Pennsylvania. Inverter efficiency has been $>99 \%$. EPRI has also funded and advanced an integrated control study.

2,360 hours were completed on $3.3 \%$ sulfur-Illinois $\# 6$ coal at the $28 \mathrm{MWt}$ CFFF; 500, 1,500, and 2,000 hours were completed on corrosion testing and analysis on the superheater, reheater, air heater, and economizer test sections at CFFF.

The Econoseed process was developed and patented. The production of 12 tons of potassium formate from spent potassium sulfate seed was successfully demonstrated in the $250 \mathrm{lb} / \mathrm{hr}$ MHD POC test unit at TRW. Preliminary tests show that the halogens are also removed, thereby, providing downstream relief of corrosion and other associated problems. 


\section{INTEGRATED \\ DEMONSTRATION DESIGN MODIFICATIONS}

The work originally performed under this contract produced a conceptual design for an MHD retrofit of a coal-fired generating plant, Montana Power Company's J. E. Corette Plant in Billings, Montana. Subsequently, MDC refined this design to incorporate the lessons learned from the ongoing POC program and altered the concept to a stand-alone rather than retrofit design. This was the design basis submitted in MDC's Clean Coal Technology V proposal.

The proposal for the BMDP incorporates the lessons learned from the POC program and is the most current, integrated design for a commercial-scale MHD demonstration. The project overview and individual system and component design requirements are therefore included in this report to reflect a concept of the demonstration that would be needed to move MHD technology to commercial application.

\subsection{PROJECT OVERVIEW}

The conceptual purpose of the BMDP was to demonstrate the significant environmental advantages and efficiency potential of MHD, one of the most innovative coal-burning technologies for future, large-station electric power generation.

At the heart of the BMDP industrial team was MDC, a corporation formed in 1985 to promote and coordinate the commercialization of MHD. Because an MHD plant is essentially two complete power systems and not a single component, it requires a broad technological base. No single equipment supplier has that technical depth or variety of commercial products. Thus, this consortium, MDC, blended the traditional power industry, regional expertise, and high technology organizations needed to develop this 21 st century 
All MHD hardware was proven through testing, and data was being collected on prototypic commercial hardware.
The technical, environmental, economic, and operating goals will be met. energy efficient technology. The Montana Power Company, the host utility and site owner, and Gilbert/Commonwealth, the project architect and engineer, represented the traditional electric power industry to ensure that the MHD power plant would be scaleable and transferable to the evolving utility industry. MSE, Inc., the operator of the CDIF in Butte, Montana, was designated the demonstration plant operator with operating personnel from the host utility. TRW was designated to provide the coal combustor and seed regeneration plant. Textron Defense Systems (TDS) was to supply the channel; the magnet was to be provided by Babcock and Wilcox; and the power conditioning system was to be provided by Westinghouse. The University of Tennessee Space Institute was to provide consultation for the heat recovery/seed recovery unit. All MHD hardware was proven through testing, and data was being collected on prototypic commercial hardware.

The project would demonstrate this 21st century technology, which followed the DOE POC program begun in 1983. The data base developed from this program represented an investment of more than $\$ 850$ million in MHD technology. The BMDP was a logical follow-up of this research and development to lead to a clean, efficient, low-cost way to utilize coal, our nation's most abundant fossil resource.

The technical, environmental, economic, and operating goals to be met for achieving this objective included:

- Demonstrate the performance and control of the integrated operation of the MHD topping cycle, bottoming cycle, and seed regeneration systems.

- Demonstrate efficiency performance at this scale, which could lead to a commercial MHD system having a net efficiency approaching $60 \%$ by the year 2030 .

- Demonstrate environmental performance that:

- removed more than $99 \%$ of the $\mathrm{SO}_{\mathrm{x}}$ emissions;

- produced nitrogen oxides emissions at less than $0.1 \mathrm{lb} / 10^{6} \mathrm{Btu}$; and 
- reduced air toxicity and carbon dioxide emissions, liquid wastes, and solid wastes more than any present technology in use or currently being developed.

- Provide financial and economic data to demonstrate the potential for competitive capital costs and resulting lower cost of electricity for the commercial scale.

- Establish operability, reliability, availability, and maintainability data of an operating system, permitting utilities to make educated decisions.

The proposed MHD project would have been a completely integrated, stand-alone, $250 \mathrm{MWt} \mathrm{MHD} /$ steam combined cycle plant located in Billings, Montana, at a site owned by the Montana Power Company. The MHD plant would have been built and operated by MDC acting as an independent power producer. The Montana Power Company and other northwest utilities would have purchased the power generated. The Montana Power Company would have provided utility plant operators, service electricity, coal, and ash disposal services. The proposed $250 \mathrm{MWt}$ BMDP was designed for primarily burning Montana Rosebud coal, generating approximately 76.8 MWe (net). The efficiency (net output divided by input) was $30.72 \%$, illustrated in Figure 2. In the test phase, other coals, such as Illinois No. 6 bituminous coal, also would have been tested. 


\section{Section 4}

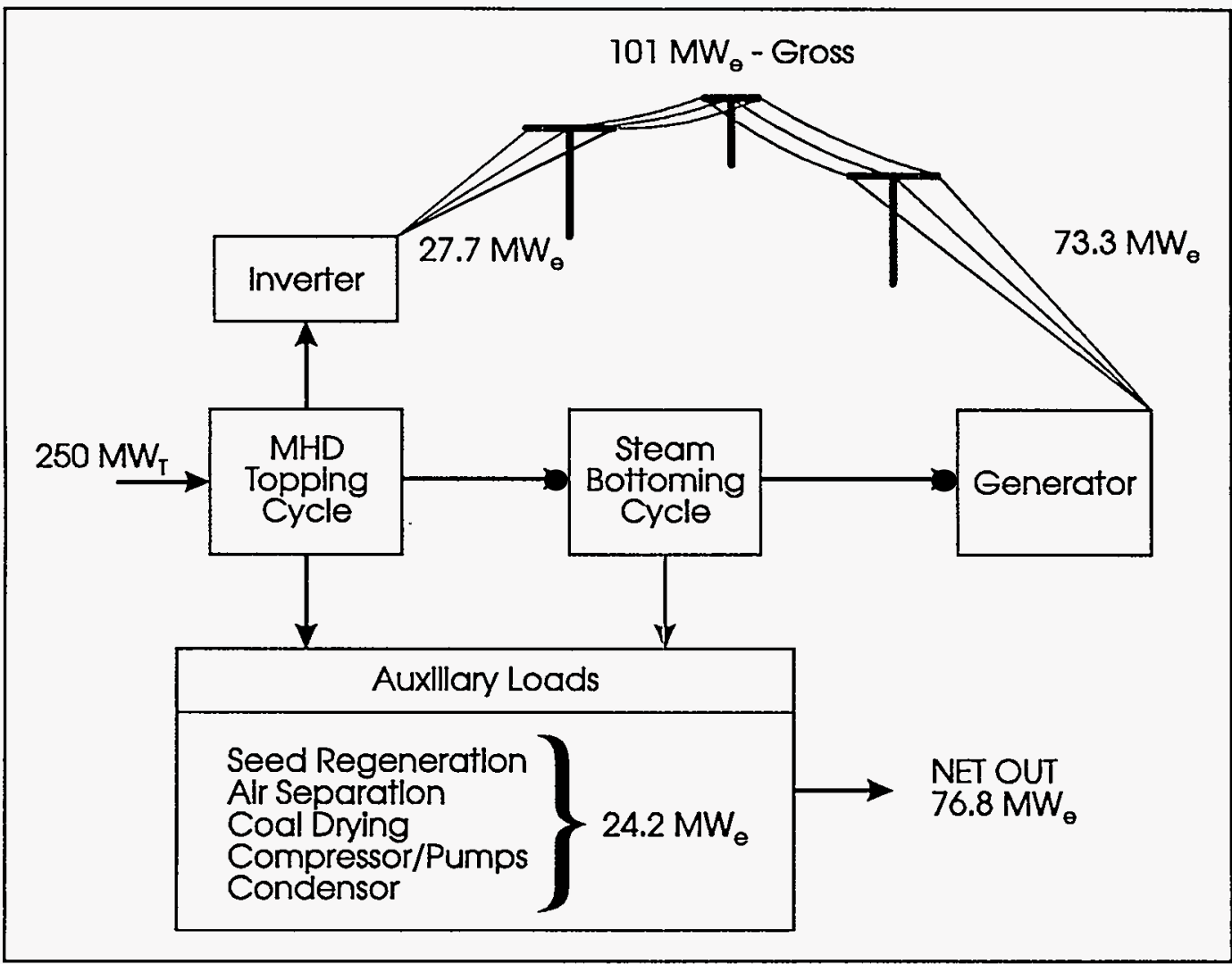

Figure 2. Efficiency Diagram.

\subsection{STAND-ALONE CONFIGURATION}

An MHD plant has flexibility in design, thereby, offering a utility the option of a retrofit (repowering) of existing plants (requiring emissions reduction) or a new, stand-alone configuration. For the BMDP, MDC selected a stand-alone design, primarily because of a noninterference with the operating J. E. Corette Plant, which is located at the same site. A stand-alone plant would not be constrained by the existing plant. A new design would use state-of-the-art components, instrumentation, monitoring and diagnostic equipment, and design practices; thereby, offering the potential for greater reliability than would result with design compromises from a retrofit. A description of the complete plant is presented later. 


\subsection{BASE LOAD OPERATION}

The proposed BMDP was designed for base load operation with no requirement for operation as a start-stop cycling unit. In general, an MHD system is operationally flexible. Plant studies have verified that MHD systems can operate as either a peaking unit or intermediate operational plant.

\subsection{PROJECT LOGIC AND TIMING}

The major steps in the development of the demonstration project are shown in Figure 3. The three phases would lead to full operation in five years.

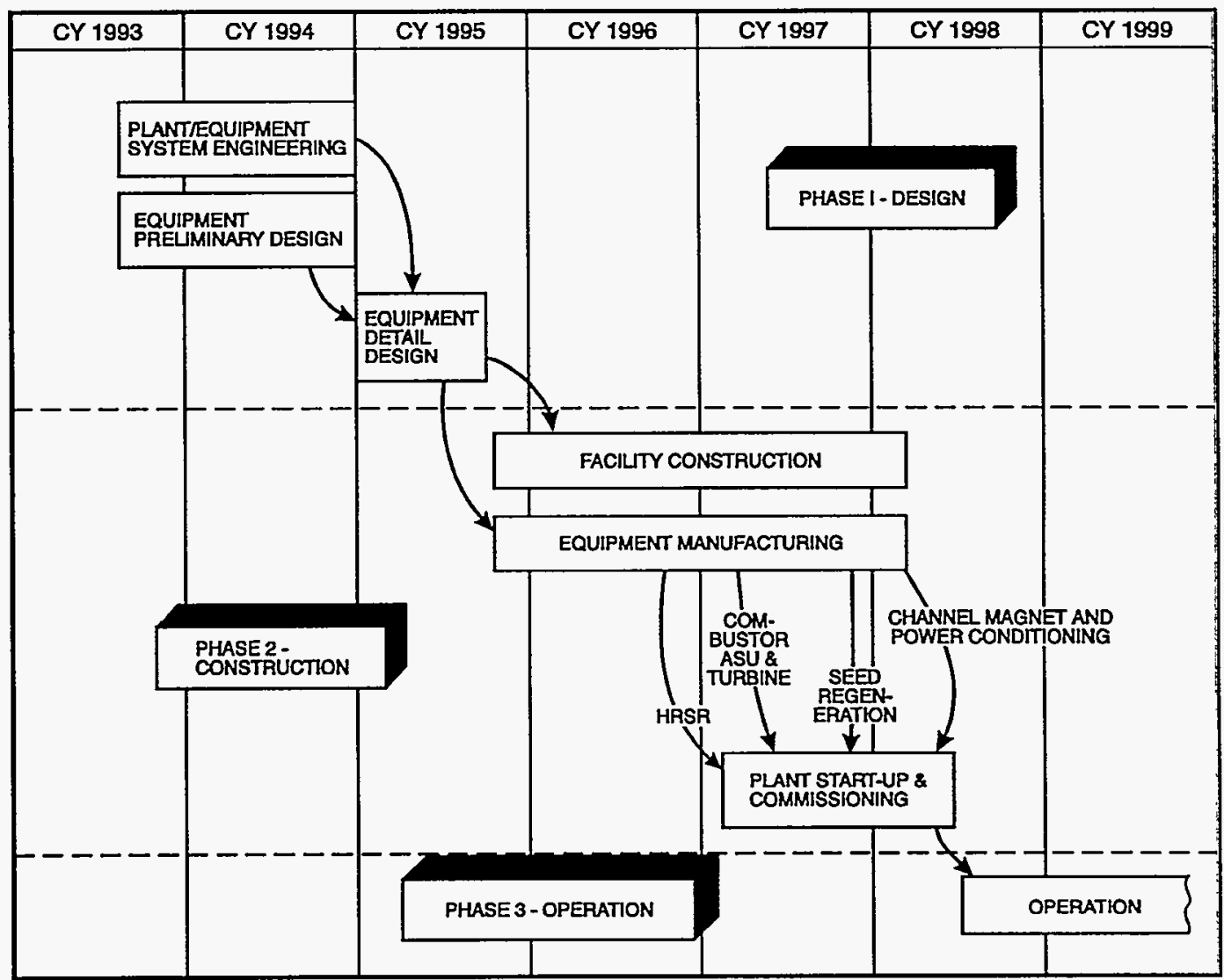

Figure 3. Demonstration Project Logic and Timing. 


\subsection{PROJECT COSTS}

The capitalized cost of the BMDP was estimated to be $\$ 416$ million. Operating costs for the demonstration phase would be an additional $\$ 104$ million. The sources of the funds reflecting $42.5 \%$ DOE funding and $57.5 \%$ non-DOE costshare are summarized in Table 1.

Table 1. Demonstration Project Funding Sources.

\begin{tabular}{||l|c|}
\hline \multicolumn{1}{|c|}{ Funding Source } & Amount (\$ million) \\
\hline \hline DOE & $\$ 221$ \\
\hline State of Montana & 53 \\
\hline Participant Funds & 206 \\
\hline Net Program Income & 40 \\
\hline Total & $\$ 520$ \\
\hline
\end{tabular}

DOE and State of Montana loans would be repaid with future profits of MHD from the licensing of the technology and other sales of MHD technology and equipment. The Bank of America loan would be repaid with revenues from the sale of electric power under long-term independent power producer contracts from the BMDP. The project would be operated as an independent power producer with the electric power being sold to the Montana Power Company and other regional utilities.

\subsection{THE MHD DEMONSTRATION PLANT}

The MHD plant would be a direct coal-fired combined cycle power plant (see Figure 4) that included an MHD topping cycle integrated with a conventional subcritical steam turbine bottoming cycle. 


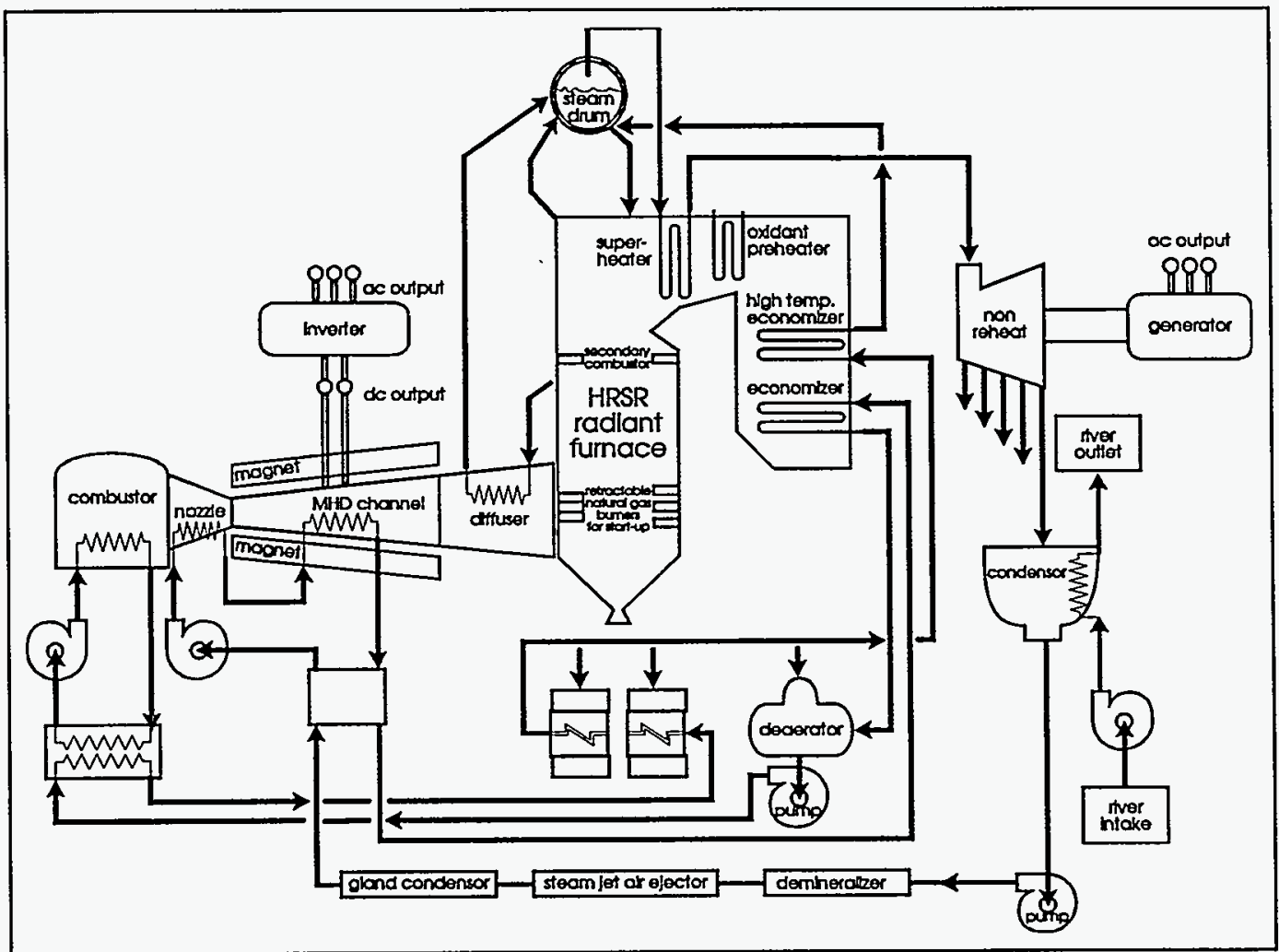

Figure 4. Billings MHD Demonstration Plant.

\subsection{KEY MHD COMPONENT DESIGNS AND PERFORMANCE}

The key design requirements and performance goals for novel MHD topping cycle hardware followed by a description of the more standard Heat Recovery/Seed Recovery System hardware are described below. Descriptions of the unique operational or design requirements needed to construct and run a large MHD plant are also included. 


\section{Section 4}

Fabrication and quality assurance procedures for the critical combustor components were developed as part of the POC program.

\section{Combustor}

\section{Design Requirements}

- coal throughput: $250 \mathrm{MWt}$ higher heating value input

- .85 stoichiometric ratio at exit

- $15 \mathrm{kV}$ operating potential, relative to ground

\section{Performance Goals}

- $>4,500^{\circ} \mathrm{F}$ exit temperature, 5.3 atm nominal pressure

- $70 \%$ slag rejection efficiency

- 30-year lifetime

- 1,500 start-ups

The combustor components are designed in accordance with ASME Boiler and Pressure Vessel Code, Section VIII, Division 2. The critical components have corrosion margins adequate for at least 20,000 hours of operation. Based on the analysis results and operational experience, the combustor system availability is 0.99 .

The combustor is designed for easy maintenance, shipment, and installation. It is made of bolted spools. Few field assembly welds would be required in the piping system for the final assembly of coolant supply lines. The design incorporates provisions for quick assembly/replacement of all consumables feed lines and in-situ replacement of the cooling panels. Fabrication and quality assurance procedures for the critical combustor components (e.g., cooling panels, primary cooling combustion chamber, and pressure shell) were developed as part of the POC program.

The $250 \mathrm{MWt}$ combustor start-up/shutdown and operational procedures would be similar to those of the $50 \mathrm{MWt}$ prototype combustor and are well understood.

\section{Channel}

Design Requirements

- thermal input $250 \mathrm{MWt}$ nominal

- supersonic channel, slagging operation

- 4.5 tesla magnetic field strength 


\section{Performance Goals}

- energy extraction (power out/heat in) approximately $12 \%$

- power output: $28 \mathrm{MW}$

- efficient part: load operation

- mean time between failures: 8,000 hours scheduled maintenance

The designs of the nozzle, MHD generator channel, and diffuser for the demonstration plant would be based on the 50 MWt POC designs. The POC generator channel design is the culmination of several successful experimental development programs and systems studies that have resulted in:

- separable wall construction for easy assembly and maintenance;

- gas-side wall designs to meet the lifetime and performance requirements;

- favorable gas-flow characteristics (no shocks and/or flow separations);

- the use of proven mechanical design/fabrication techniques; and

- successful operation at prototypical conditions.

The demonstration channel is constructed from four separable walls that are bolted and sealed at the corners to form a rectangular, cross-sectioned duct. The channel is 36- $\mathrm{ft}$ long and weighs about $45,000 \mathrm{lbm}$. Each channel wall is fabricated in two, 5.5-meter (18 ft) sections joined at a midjoint flange. The boxed walls function as the structural shell and as the pressure vessel. The walls are fabricated from fiberglass laminate sheets 0.15 -meter $(5 \mathrm{in}$.) thick that have electrodes and sidewall bar elements mounted directly onto the boards.

Plant availability has a direct bearing on the cost of electricity, hence, plant profitability. Therefore, a planned outage maintenance concept would be used to extend the mean time between failures. Two MHD generator channels would be in alternate service. These two channels are swapped during the planned plant maintenance times. Worn electrode and/or sidewall elements would be replaced or repaired in the generator channel that was not in service.
The POC generator channel design is the culmination of several successful experimental development programs and systems studies.
Two MHD generator channels would be in alternate service. 


\section{Section 4}

A conservative estimate for the planned replacement of the nozzle is after 8,000 hours of operation (equivalent full year operation). Replacement of the diffuser adjacent to the channel, which is exposed to the magnet fringe field, is also estimated to be 8,000 hours.

The estimated inherent operating availabilities of the nozzle/channel/diffuser are shown in Table 2.

Table 2. Availability Estimates.

\begin{tabular}{||l|l|l|l||}
\hline & \multicolumn{1}{|c|}{ A } & $\begin{array}{l}\text { MTBF } \\
\text { Hours }\end{array}$ & $\begin{array}{l}\text { MTTR } \\
\text { Hours }\end{array}$ \\
\hline Nozzle & 0.997 & 16,000 & 50 \\
Channel & 0.989 & 6,000 & 65 \\
Diffuser & 0.998 & 20,000 & 50 \\
\hline \multicolumn{3}{|c||}{ MTBF } \\
Availability A $=\frac{\text { MTBF - MTTR }}{\text { where MTBF }=\text { Mean Time Between Failure }}$ \\
where MTTR $=$ Mean Time To Replace \\
\hline
\end{tabular}

The designs of the demonstration MHD nozzle/channel/ diffuser components are based on tried and proven designs. Experimental work obtained on prototypic components has verified the necessary performance and lifetime characteristics of those MHD topping cycle power train flow components to proceed with the proposed BMDP.

\section{Power Management System}

Design Requirements

- power take-off: 100 anodes/75 cathodes

- consolidation output: single, two-current source inverter

- maximum circuit current: $80 \mathrm{amp}$

- maximum consolidation current: $3.5 \mathrm{kA}$

- maximum consolidation voltage: $20 \mathrm{kV}$

- total power: $30 \mathrm{MWe}$

- AC interface: $100 \mathrm{kV}$ 


\section{Performance Goals}

- $>95 \%$ conversion efficiency

- 30-year lifetime

- 0.998 availability

The power management system converts the dc output of the MHD channel to ac grid quality electric power. The design is derived from the MHD POC program. All equipment uses commercially available power electronics technology.

The power management system is comprised of two subsystems. The current control subsystem prevents the transfer of cathode nonuniformities to the anode wall of the channel. The power conditioning subsystem converts the dc power from the channel electrodes to ac power at the utility grid. This conversion takes place in two stages. In the first stage, the current from the many channel electrodes in the power take-off regions are consolidated to a single dc bus. The equipment termed current consolidators performs this function. The system contains 100 consolidation circuits on the anode side and 75 circuits on the cathode side. In the second stage, the inverter converts the consolidation dc to ac and is comprised of three separate power circuit functions. The key component is a conventional, current-sourced, linecommutated selective catalytic reduction inverter performing the required dc-to-ac conversion.

\section{Superconducting Magnet}

Design Requirements

- flux density: 4.5 tesla

- active field length: $36 \mathrm{ft}$

- bore diameter: $6.6 \mathrm{ft}$

Performance Goals

- 30-year lifetime

- 500 start-ups

- 98\% availability

- $100 \mathrm{~kW}$ refrigeration power

The Babcock and Wilcox superconducting magnet system (SCMS) provides the magnetic field in the MHD channel for operating the topping cycle. The SCMS proposed is based on 


\section{Section 4}

existing magnet designs and operating experience. Table 3 lists the SCMS operating specifications.

Table 3. SCMS Operating Specifications.

\begin{tabular}{||l|l||}
\hline 1. Magnet Bore Length & $11.0 \mathrm{~m}$ \\
\hline 2. Bore Diameter & $2 \mathrm{~m}$ \\
\hline 3. Maximum On-Axis Flux Density & $4.5 \mathrm{~T}$ \\
\hline $\begin{array}{l}\text { 4. Approximate Overall Magnet } \\
\text { Dimensions }\end{array}$ & $\begin{array}{l}\text { Length } 13 \mathrm{~m} \\
\text { Diameter } 8.5 \mathrm{~m}\end{array}$ \\
\hline 5. Magnet Charge Time & $\begin{array}{l}1 \mathrm{hr} \text { with } 0.5 \mathrm{MW} \\
\text { power supply }\end{array}$ \\
\hline 6. Refrigeration Power Requirements & $100 \mathrm{~kW}$ \\
\hline 7. Helium Coolant Temperature & $4.5 \mathrm{~K}$ \\
\hline 8. Lifetime & $30 \mathrm{years}$ \\
\hline 9. Total Start-ups & 500 \\
\hline 10. Magnet Availability & $100 \%$ \\
\hline 11. System Availability & $98 \%$ \\
\hline 12. MHD Support Load Channel & 25 tons \\
\hline 13. Estimated Cryostat Weight & 250 tons \\
\hline
\end{tabular}

Operation of the magnet system encompasses two separate system cycles. The thermal system cycle involves either cool down or warm-up of the cold mass. The electrical system cycle involves the charge/discharge of the magnet. Thermal cycling of the magnet would require several weeks, and only a few thermal cycles of the magnet over the system's 30-year lifetime are anticipated. Electrical cycling would occur more frequently. Both thermal and electrical cycling are standard practice and represent no inherent risk. 
Experience with SCMSs indicates that they are highly reliable. Most magnet failures result from mechanical failure of the insulation. The choice of conduction in conduit construction permits unbroken insulation of the conduit with accompanying maximum insulation strength.

The fabrication plan for the SCMS focuses on the magnet and cryostat. The remaining components of the system would be purchased from established, qualified vendors and shipped to Babcock and Wilcox for use in the system testing program and then to Billings, Montana, for on-site installation. The magnet and cryostat would be fabricated at Babcock and Wilcox Accelerator and Magnet Systems in Lynchburg, Virginia. The baseline fabrication plan takes advantage of the experience gained in fabricating the Argonne MHD SCMS, and the SCMS would be wound as that magnet was wound. Thus, the fabrication of the SCMS is a proven methodology. The SCMS would be fully tested before shipping to the Billings site. The magnet would be disassembled and the cold mass would be shipped as a unit. The remaining parts would be shipped in pieces and reassembled on site.

\section{Heat Recovery/Seed Recovery (HRSR) System}

Design Requirements/Features

- inlet temperature to primary furnace: $4,000^{\circ} \mathrm{F}$

- primary stoichiometry: 0.85 to secondary combustor

- refractory boiler lining to minimize corrosion from molten potassium seed, $600^{\circ} \mathrm{F} / \mathrm{sec}$ cooling rate

- boiler fixed at bottom (on MHD channel centerline) and supported by power springs to permit vertical growth (additional flexibility required for riser and supply tube expansion)

\section{Performance Goals}

- $\mathrm{NO}_{\mathrm{x}}<0.10 \mathrm{lb} / 10^{6} \mathrm{Btu}$

- near $100 \%$ sulfur and chlorine removal

- particulate emissions $<0.01 \mathrm{lb} / 10^{6} \mathrm{Btu}$

The HRSR system has a subcritical, drum-type boiler with a gas inlet temperature of $3,950^{\circ} \mathrm{F}$ entering the upstream wall of the boiler through an 8-ft-by-6-in. circular opening. The boiler is designed as a wet bottom boiler with a slag tap to an

The fabrication of the SCMS is a proven methodology. 


\section{Section 4}

atmospheric pressure, water-filled tank to handle the slag not collected in the primary combustor.

The HRSR boiler differs slightly from conventional utility boilers as described below:

- The primary furnace to the secondary combustor would be in a reducing gas zone, stoichiometry approximately 0.85 . The walls of this part of the boiler would be wet slag coated walls. The construction of the furnace walls would be similar to the membrane wall construction, used in black liquor boiler construction except that the walls are studded and 1-in. thick refractory coated with a rammed mix refractory (similar studs and refractory have been used by the Tennessee Valley Authority in Babcock and Wilcox cyclone combustors).

- The boiler would be fixed at the center line of the MHD generator. The drum would be fixed on the top to the boiler structure. The boiler would be power spring supported to allow the boiler to expand upward. Therefore, the risers and supply piping between the boilers and the drum would have sufficient flexibility to allow for the upward expansion of the boiler. The heat removal from the two expansion chambers and the divergent sections of the diffuser are included in the boiler surface. This surface enters the boiler and forms a division wall partially across the middle of the boiler.

\section{Seed Regeneration Process}

\section{Design Requirements}

- seed throughput: 7,630 Ib/hr (dry), based on 1\% potassium in channel

- reject $100 \%$ of coal chlorine and sodium absorbed by seed

- reject $99.9 \%$ coal sulfur in an environmentally favorable fashion

$-\mathrm{K}_{2} / \mathrm{S}>1.4$ in seed

\section{Performance Goals}

- maintain chlorine levels $<0.2 \%$ in recycled seed

- produce a recycle seed with $<5 \%$ moisture and $<0.5 \%$ sulfur 
The seed regeneration system recycles the potassium seed used to enhance the conductivity of the plasma in the MHD channel. An important secondary function of the seed is to capture coal sulfur, which the seed regeneration system converts to environmentally acceptable gypsum that has the potential for resale.

The seed regeneration process is a small but key aspect to the overall MHD power system. Econoseed is a chemical seed regeneration process tested as part of the POC program. This process uses, as feed, the spent seed material collected in the baghouse or electrostatic precipitator and the HRSR. The spent seed is processed to regenerated seed, a mixture of potassium formate and potassium carbonate, which is pumped to the seed feed system. The seed is injected into the combustor prior to the channel as a liquid slurry. The sulfur captured by the seed is rejected by the seed regeneration process in an environmentally acceptable solid gypsum.

Initial models using the Econoseed process indicate that the economics associated with seed regeneration are very important in the overall economics of the demonstration facility. Other seed regeneration schemes exist and were proposed early in the POC program. A scheme based on ion exchange has the potential for favorable economic performance and could be more acceptable since other normal utility operations use ion exchange equipment. Early in the design of the demonstration facility, tradeoff processes and studies would have to be completed to optimize this function.

\section{Demonstration Facility Site}

The proposed site for the demonstration plant is located next to the Montana Power Company's J. E. Corette Plant. The Corette plant is located on a 70 -acre site near Billings, Montana. The plant is served by the Burlington Northern Railroad and is located adjacent to the Yellowstone River. The Billings location offers all the amenities necessary to support the construction and operation of this facility.

Enhancement of the local environment, particularly air quality, Enhancement of the local environment, particularly air quality, is a primary objective of the BMDP/J. E. Corette site-sharing plan.

The economics associated with seed regeneration are very important in the overall economics of the demonstration facility. is a primary objective of the BMDP/J. E. Corette site-sharing plan. 


\section{Section 4}

Tests show that, in addition to superior sulfur emission control, nitrogen oxides, particulate emissions, and air toxics are also well controlled in MHD plants. Table 4 summarizes the total emissions expected annually from the plant.

Table 4. Expected Air Emissions From the BMDP.

\begin{tabular}{||l|l|l|l|l||}
\hline \multicolumn{2}{||}{ Net Plant Output: $76,806 \mathrm{~kW}$} \\
\hline Net Plant Heat Rate: $11,636 \mathrm{Btu} / \mathrm{kWh}$
\end{tabular}


Section 5

\section{REMAINING OPEN ITEMS}

The demonstration proposed by MDC was based on the assumption of successful completion and outcome of the POC testing. Technical risks were itemized, and planned mitigation was outlined. Open items were addressed in that mitigation, and an acceptable level of risk attained.

Independent of MDC, two separate studies performed in 1993 each addressed the remaining technical issues. Included below are excerpts from those reports.

\section{GAO Report:}

...According to a DOE commissioned November 1990 assessment of the POC program by an independent panel of private sector experts, the most important POC testing goal is to demonstrate the durability of the topping cycle components. The assessment questioned whether even the planned 1,000 hours of testing would be adequate to allow for sufficient data to be collected and analyzed to demonstrate the durability of the MHD generator and other critical components of the topping cycle system. The assessment emphasizes that the allotted time for duration testing should be increased to increase the probability of success and pointed out that utilities need such data on which to base a decision on pursuing MHD as a future technology to commercialize.

A number of problems or uncertainties are associated with MHD technology involving slag removal in the combustion chamber, durability of the channel, cost-effectiveness of the seed regeneration process, performance of fully integrated components, and potential scale-up problems as increasingly larger MHD systems are built. Also some new, advanced technologies are needed if MHD efficiencies are to exceed those of competing coal technologies that are further developed than $M H D$... 


\section{Section 5}

A. D. Little Report:

...However there are still some areas where the engineering data base for building the next-step, 50 to 100 $M W e$ integrated demonstration plant, is incomplete. The following issues should therefore be addressed before proceeding to the next step, integrated demonstration plant project:

- topping cycle durability;

- combustor secondary zone oxidant effects;

- topping cycle operation on Eastern coal;

- topping cycle operation with high temperature coolant;

- channel packaging/magnet bore utilization;

- use of potassium formate seed;

- regeneration of spent seed from Western coal firing;

- integrated seed regeneration plant operation;

- seed regeneration plant durability;

- trace impurity control; and

- integrated MHD system operation and control.

Because the POC program was not completed as originally planned, and certain aspects were dropped from the program, the technical issues must be reassessed, mitigation measures redefined where applicable, and the risk associated with going to the next step of development must be reevaluated. 
Section 6

\section{PERSPECTIVE ON GOVERNMENT AND INDUSTRIAL TECHNOLOGY DEVELOPMENT}

A need exists for developing advanced coal-fired technologies, specifically MHD. That need is addressed generally in DOE's Fossil Energy Strategic Plan. In addition, utility market studies indicate that there will be a window of opportunity for the deployment of this type of technology.

\section{The U.S. Government's Strategic Plan for Advanced Coal} Technology, September 17, 1992, as well as the budget language in the administration's request for FY-94 describe the current fossil energy strategic plan. These documents recognize that current electrical power generation needs can be fulfilled with natural gas. However, as the requirements for additional and replacement capacity are realized in the beginning of the next decade for coal burning facilities to continue to be economically competitive, there will be a need for advanced technology to meet the anticipated new cost and environmental standards of the day.

The FY-94 fossil energy budget request focuses on the following strategic objectives:

- by 2000 , achieve $42 \%$ efficiencies...and $1 / 3$ Clean Air Act's New Source Performance Standards (NSPS);

- by 2005, achieve $47 \%$ efficiencies... and $1 / 4$ NSPS;

- by 2010 , achieve $55 \%$ efficiencies...and $1 / 10$ NSPS plus toxic emission reductions and cost of electricity 10 to $20 \%$ less than the current cost; and

- by 2015 , achieve $60 \%$ efficiencies... while meeting 2010 environmental and economic performance goals.

These goals are in concert with the DOE Strategic Plan for Advanced Coal Technology that states:
The FY-94 fossil energy budget request focused on achieving $55 \%$ efficiencies and $1 / 10$ NSPS, plus toxic emission reductions and electricity costing 10 to $20 \%$ less by 2010 . 


\section{Section 6}

A panel comprised of primarily industrial and utility representatives provided the electrical industry perspective.
Performance Goal: Demonstrate by the year 2010 advanced coal technologies with more than 55\% efficiencies. These systems must also control $\mathrm{SO}_{2}, \mathrm{NO}_{x}$, and particulate emissions to one-tenth of New Source Performance Standards. Toxic emissions should meet the yet-to-be-defined levels, and solid waste must be nontoxic and at least $50 \%$ must be marketable. Finally the cost of electricity must be less than the cost of natural gas combined cycle systems as estimated for the year 2010.

To meet these challenging goals, the program looks to two highly advanced technologies: fuel cells and magnetohydrodynamics (MHD)...

That same strategic plan projects MHD systems as having the highest potential efficiency of any advanced coal system currently being developed.

In addition to the strategy and budget documents cited above, President Clinton and Vice President Gore's published Technology for America's Economic Growth: A New Direction to Build Economic Strength, February 22, 1993, provides greater insight into the strategy for technology development as a whole and can apply directly to technologies such as MHD and the role of government in its development.

A panel discussion (comprised of primarily industrial and utility representatives) was held at the 31 st Symposium on Engineering Aspects of Magnetohydrodynamics, July 1, 1993. This panel provided an understanding of the United States' electrical industry perspective on the power market and the ability of MHD to enter that market. That perspective was complementary to that developed and used to obtain utility support of the BMDP and as part of the commercialization plan of the Clean Coal Technology V proposal. Several of the premises from that discussion are listed below:

- Natural gas will probably be the fuel of choice for electrical generation for the next 20 years based on economics. At that time, however, gas supplies will become more limited and more expensive. The United States will then have to rely upon coal at least until the nuclear (or other) options become viable, both politically and economically. 
- Coal will not be a viable and economic fuel of choice without efficiency and pollution control improvements.

- More than $50 \%$ of our existing generation is from coal. Replacement of the existing coal plants will cost the utilities $\$ 10$ billion/year $(250,000,000 \mathrm{~kW} \times \$ 2,000 / \mathrm{kW} \times 1 / 50$ year). Thus, even if 2010 is a few years away, $\$ 100$ million now for potentially the best coal-burning technology makes sense.

- Independent power producers are very active now because they can offer small gas-fired units financed from power sale contracts. Large coal units will be a different matter, and the utility companies will again have the responsibility to serve. Public service commissions are recognizing this fact and are not releasing utilities from this responsibility.

- It is difficult to have enthusiasm for investing now in a technology that will not be commercial until the year 2010; but if this demonstration is not supported now, the technology will not be available when it is needed.

- MHD has the potential to be the most cost effective, clean coal burning, and efficient way to utilize our huge coal resource.

- Almost $\$ 850$ million has been spent on the development of MHD, and the technology is now ready for demonstration. Utility companies cannot support such a demonstration and will not buy into the technology until it is economically feasible. The Clean Coal Technology Program targets such a technology as this-longer term, new technology with the potential to significantly advance the efficiency and environmental performance of coal for the 21 st century. However, it is not clear that there will be future Clean Coal Technology solicitations, nor that MHD would be able to compete with nearer term technologies.

- This opportunity to develop the technology may not exist later. The consortium of eight companies have expert teams ready now, but these teams may not exist at a later date.

Almost $\$ 850$ million has been spent on the development of MHD, and the technology is now ready for demonstration.
Replacement of the existing coal plants will cost the utilities $\$ 10$ billion/year. 


\section{Section 6}

As part of its report on MHD, the A. D. Little Company conducted interviews with eight electric utility companies concerning generation planning and advanced power generation technology selection criteria. Excerpts from this report provides further insight into the utility role in new technology:

...The consensus among the companies interviewed is that levelized cost of electricity is the paramount criterion used in making generation planning decisions. Environmental performance is also of primary importance. Reliability is considered indirectly through measures such as levelized cost. Reliability levels for advance power generation technologies will be required to be consistent with those for conventional pulverized coal plants...The companies interviewed had no concerns regarding MHD technology per se, and emphasized that technology selections will be made primarily on economic and environmental grounds. 


\section{OPTIONS FOR THE FUTURE OF MHD}

The following are options for the future of MHD. The options are not listed in any particular order of priority nor are they independent of each other (several may have to be exercised at the same time).

- Establish a strong industrial champion-a developer utility company or team capable and willing to support the further development and commercialization of MHD technology.

- Wait until Clean Coal Technology VI or similar government-aided program and submit another proposal for the BMDP.

- Construct a demonstration at another location with a more fundable basis (better electrical price, state support, political support, etc.) and submit this proposal for Clean Coal Technology or other cost-share funding support.

Establish a strong industrial champion.

- Generate within Congress an initiative for a direct procurement for the BMDP funded by the excess Clean Coal Technology dollars that have not been spent to date.

- Redo a retrofit concept for the J. E. Corette Plant, the Bird Plant or other similar facility using the Argonne superconducting magnet and a scaled-down project.

- Initiate another phase of the development program by upgrading the CDIF (or CFFF) to perform the next generation of tests (i.e., move superconducting magnet; install boiler; and run tests at $100 \mathrm{MWt}$, producing about $5 \mathrm{MWe}$, from the MHD side and $30 \mathrm{MWe}$ from the bottoming cycle for a net of $\sim 30 \mathrm{MWe}$ ). 


\section{Section 7}

Develop other industrial applications.
- Build the BMDP as envisioned (or similar plant) without Federal funding support.

- Establish MHD as a technology that would fulfill each of the stipulations of the Clinton-Gore view of technology, thereby, providing the basis for a reinstituted development plan jointly funded by the Federal Government and industry.

- Reconstitute a DOE-funded national program to complete the original scope of the POC and extend that program to encompass the developmental issues required to commercialize the technology.

- Institute a research and development program nominally funded to address MHD long-term developmental needs.

- Restructure a national research and development program based on other cycles (e.g., closed cycle or disk generators) in partnership with the Japanese.

- Develop other industrial applications (electricity, effluent, and heat) to economically use that which is proven about MHD and to provide for its future development.

- Develop alternative federal funding sponsors for portions (or all) of the technology, such as space applications with NASA.

- Initiate an entirely new program funded solely by DOE and located in the eastern United States.

- Work with a foreign entity (i.e., China) for the next phase of MHD development and then try to capture it back for our use when the technology is advanced.

- Archive existing information and wait until economics warrant further MHD technology development. 


\section{CONCLUSION}

An identified need and future market exists for coal-fired MHD technology. The development of the technology has advanced to where the next stage would be the demonstration to prove its economical performance. Over $\$ 850$ million in investment has been made by both the Federal Government and the private sector to reach this point of the first large-scale MHD demonstration. Based on the progress made to date, the results of the POC program, and the opportunity for joint funding of the demonstration, the developing industry invested significant additional funding and proposed a $60 / 40 \%$ costshared project to provide this demonstration. The proposal was not able to compete with other nearer term technologies, and in fact, probably was not suitable for the Clean Coal Technology.

The POC program has been concluded, and the teams and testing facilities are being dismantled.

The A. D. Little report, which reviewed the major aspects of the MHD POC program in great detail, concluded that the development of MHD power generation technology, with its potential for efficient and environmentally acceptable power generation from coal, should be continued to complete the data base required to allow the private sector to decide whether to proceed to the demonstration plant stage.

Industry: and government must come together to chart a course.

Industry and government must come together to chart a course that will provide for the demonstration and further development of this technology. Without an avenue along which to proceed, most of the investment will be lost. More concerning, the potential of a technology that could fulfill this country's need for a clean, efficient power source powered totally by domestic fuel, as well as provide American technology to the developing third world countries, will be lost. 



\section{APPENDIX A: GLOSSARY}

The glossary in this Appendix is a paper that was published by A. T. Hart, et al., "Compendium of MHD-Unique Terminology," Proceedings for 27th

Symposium on Engineering Aspects of Magnetohydrodynamics, Reno, Nevada, June 27-29, 1989, pp. 0.1-1 thru 0.1-14. 


\begin{tabular}{|c|c|c|c|c|}
\hline $\begin{array}{l}\text { A. T. Hart } \\
\text { Senior Test Engineer } \\
\text { Component Development } \\
\text { and Integration } \\
\text { Facility } \\
\text { MSE, Inc. } \\
\text { Butte, MT } 59702\end{array}$ & $\begin{array}{l}\text { D. Lofftus } \\
\text { Senior I\&C Engineer } \\
\text { Component Development } \\
\text { and Integration } \\
\text { Facility } \\
\text { MSE, Inc. } \\
\text { Butte, MT } 59702\end{array}$ & $\begin{array}{l}\text { R. J. Rosa, Ph.D } \\
\text { Professor of Mechanical } \\
\text { Engineering } \\
\text { Hontana State University } \\
\text { Bozeman. MT } 59717\end{array}$ & $\begin{array}{l}\text { J. N. Chapman, Ph.D } \\
\text { Manager of Advanced } \\
\text { Energy Conversion } \\
\text { R\&D Programs } \\
\text { University of Tennessee } \\
\text { Space Institute } \\
\text { Tullahoma, TN } 37388\end{array}$ & $\begin{array}{l}\text { Y.C.L. Susan Hu, Ph.D } \\
\text { President and CEO } \\
\text { Engineering Research } \\
\text { and Consulting, Inc. } \\
\text { Tullahoma, TN } 37388\end{array}$ \\
\hline
\end{tabular}

\section{ABSTRACT}

The magnetohydrodynamic (MHD) researchers in the United States have joined together in the past few years to prove the viability of the technology. As new designs for hardware, methods of operation. approaches for data analysis, and levels of understanding have been attained, a set of MHD-unique terminology has been developed but not always documented. A glossary of terminology unique to the study of MHD has been compiled to provide an information source for workers in this field, and to assist those interested in the commercial potential of MHD in reading and understanding technical articles on the subject. The terminology defined here is related primarily to the U.S. proof-of-concept program of MHD development, which is geared toward retrofitting a coal-fired power plant with MHD equipment. Basic theoretical terms as well as terminology related to the commercialization of MHD are defined. Emphasis has been placed on terms related to commercialization and those related to currently active areas of study. This paper represents the first step toward developing a standardized vocabulary of MHD-unique terminology, and transferring this technical vocabulary to potential users.

\section{INTRODUCTION}

Scientists and engineers in the United States have been involved in the research and development of magnetohydrodynamics (MHD) technology for power generation since the late 1950s. This research and development (R\&D) is now primartly sponsored by the U.S. Department of Energy through contracts with research organizations and component developers and through the operation of two major test facilities, the Component Development and Integration Facility (CDIF) in Butte, Montana and the Coal-Fired Flow Facility (CFFF) in Tullahoma, Tennessee. In recent years, a technology base has been developed for MHD components, and proof-of-concept development and demonstration has begun toward eventualiy retrofitting a coal-fired power plant with MHD process equipment (commercialization).

In the MHD process being developed in the U.S. (Figure 1), coal is burned with a seed material (commonly a potassium compound) in a high-pressure combustor to produce an electrically conducting plasma. The pressurized working fluid leaving the coal combustor is accelerated through a nozzle and expanded through an MHD channel. Direct-current electrical power is extracted through a series of channel electrodes as the gas flows through the transverse magnetic field within the channel. The gases leaving the channel are decelerated within a diffuser. The energy in the diffuser exhaust gas is recovered in a bottoming cycle, and is used to generate steam for producing electric power. augmenting the power produced in the MHD topping cycle. This is accomplished by passing the exhaust gases through a heat recovery/seed recovery (HRSR) system--a series of heat exchangers in which slag. seed, and ash are removed; heat is recovered by generating steam; and potassium compounds are recovered, regenerated to seed, and reinjected into the combustor.

The technical disciplines involved in developing MHD for commercial power applications are many and diverse. They include electrical engineering. mechanical engineering, plasma physics, chemical engineering, materials science, and aerodynamics, to name a few. In this multidisciplinary development environment, new hardware designs, methods of operation, and approaches to data analysis have been developed. The set of MHDunique terminology that has arisen from these recent developments has been documented primarily in papers presented at technical symposia; however. due to the rapid rate of technology development and the multidisciplinary and decentralized nature of the ongoing R\&D, no concise central reference work has yet been published that provides definitions for the varied terminology in current widespread use. This paper is an attempt to fill this void in the MHD Iiterature.

To make this compendium more useful, terms have been grouped into two categories: those used solely or primarily to describe the basic physics involved in MHD phenomena, and those used solely or primarily to describe the application of MHD to commercial power generation. The first section of this paper defines terms related to basic MHD theory, while the second defines applicationsoriented terms. A bibliography of MHD literature and reports is also provided. 


\section{TERAINOLOGY}

\subsection{BASIC THEORY}

In this section. an effort was made to include terms oriented toward the solution of theoretical problems involved in achieving commercialization. Terms are grouped according to subject. Terminology applicable to MHD in general and MHD channels in particular, are followed by terms used for gasdynamic, electrical, and polarization effects. A listing of MHD-related factors and parameters, a discussion of equilibrium/nonequilibrium terminology, and definitions of spatial conventions conclude this section.

\subsection{GENERAL TERAS}

Terms that have no particular affinity for a specialized subfield are given below.

Magnetohydrodynamics (MND) - In general, the study of the motion of electrically conducting fluids, liquid or gaseous, in a magnetic field. The term MHD is applicable not only to electric power generation, but to a wide and growing number of other areas: blood flow measurement. the origin of and changes in the earth's magnetic field, sunspots, solar flares, black holes, and other astronomical phenomena, pumps for corrosive liquids, nuclear fusion, and circuit breakers.

Magnetohydrodynamics (MiD) - Specifically, as used in this paper. MHD is a process for power generation and extraction using an electrically conducting fluid moving across a magnetic field. A typical, more restrictive usage is for an open-cycle process using combustion gases from a hydrocarbon fuel as the fluid. The associated technology is being developed for use in a commercial application to stretch known hydrocarbon fuel resources through improved efficiency.

Generator - A piece of hardware that confines the working fluid within a magnetic field. Electrical power is drawn through wiring to attached electrodes that make up part of the generator walls.

Accelerator - An MHO generator working inversely (e.g.. motor vs. generator) where the working fluid is accelerated by absorbing electrical energy supplied from an external source. It may be used to increase the velocity of the working fluid.

Working Fluid - The fluid, typically an ionized gas or plasma, that flows through the MHD generator to produce electrical power. This term is often used interchangeably with plasma or gas stream.

Closed-cycle - In MHD, a thermodynamic cycle in which the working fluid, a seeded inert gas or a liquid metal, is heated externally and recycled through the generator.

Open-cycle - In MHD, a thermodynamic cycle in which the working flufd, generally combustion products, is used on a one-pass basis.

Enthalpy Extraction - Percent of the sensible enthalpy (1.e.. above $1 \mathrm{~atm}, 298 \mathrm{~K}$ ) of the gas entering the generator that is delivered to the external circuit as electrical power. This term should not be confused with either generator. cycle, or plant efficiency. For example, it is possible for the enthalpy extraction to be twenty percent in a cycle with fifty percent efficiency.

MID Waves - Oscillations that can result (under certain circumstances) from the interaction of a conducting fluid with a magnetic field. The best known is the Alfein wave discovered by Swedish scientist Hans Alfein who won a Nobel prize for his work in MHD.

\subsection{GENERATOR CONSTRUCTION}

Numerous generator construction methods have been tried, each with its own advantages and disadvantages. The two basic types of construction are disk and linear generators. There are a number of variations of each of these. The details of generator construction for commercial application are given in the section titled Channel Technology.

Disk Generator - An MHD generator configured like a disk in which gas enters at the center and exits at the edge; consequently, the gas flow is radial. The magnetic field is perpendicular to the disk. and power is extracted by ring-shaped electrodes near the center and edge. A disk generator is a Hall generator; however, inlet swirl can be applied to make the disk generator a diagonal conducting wall (DCW) generator.

Linear Generator - A design where the path of the working fluid is a straight 3 ine. The generator is typically rectangular and diverges from the inlet to the outlet. A linear generator is also called a channel.

Diagonal Conducting Wa11 (DCH) Generator - A design where the cathode and anode are connected by a conducting wall rather than by external connections. The wall is made of metal bars placed at an angle to the plasma flow. The Hall effect and desired loading determine the angle chosen for the metal bars.

Hindow Frame Generator - A design in which electrodes and sidewalls are in one piece. This design is a specific example of a DCW generator. and is called a window frame generator because each electrode/sidewall piece resembles a window frame.

Segmentation - A construction method in which the channel is electrically isolated into segments along its length to prevent power loss that would result from shorting of the Hall field.

Continuous Electrode Generator - A channel without segmentation.

\subsection{GASDYNAMIC EFFECTS}

The challenges of MHD for gasdynamicists are many. Applying theoretical concepts to a plasma flowing near or above supersonic speed through powerful interacting electromagnetic fields has given rise to many application-specific terms.

Gasdynamics - The science of fluid mechanics or fluid dynamics applying to a gas when its compressibility becomes important (i.e., when the Mach number is not negligible (e.g.,>0.3)). 
Aerothermal Boundary Layer - The layer of gas flow near the generator walls that is cooler and slower Ihan the gas flow near the center of the generator.

Separation - Failure of the gas flow to follow the contour of the wall. This occurs when pressure rises or velocity in the direction of the gas flow decreases.

Nonuniformity - In MHD, this generally refers to the condition of the plasma, which has an important effect on performance.

Interaction Length $\left(L_{i}\right)-A$ measure of the flow length required to achieve a significant effect on the pressure or the velocity of the gas flow. Its mathematical definitions are:

$$
L_{1, U}=\frac{\rho U}{\sigma B^{2}} \text { or } L_{1, p}=\frac{p}{\sigma U B^{2}}
$$

Interaction Parameter (I.P.) - The number of interaction lengths in an MHD device. For an MHD generator this nondimensional number will typically be two to four.

$$
\text { I.P. = (length of device) } / L_{i}
$$

Core flow - Gas flow along the centerline of the channel. Typically, this is where the gas is hottest and has the highest velocity.

Secondary flows - Flows in the cross-sectional plane of a generator induced by transverse body force due to strong and nonuniform Hall current.

\subsection{ELECTRICAL EFFECTS}

The purpose of MHD is electrical power generation; therefore, it is expected that emphasis would be placed on the associated unique electrical effects. Many of the terms listed.below arise not only in the context of internal generator electromagnetics, but also in externally observed electrical phenomena.

Conductivity - A measure of the ease with which electric current can pass through the gas. Units of measure are siemens/meter (previously mhos/meter) or 1/ohm-meter. Since plasma conductivity varies along the length of the channel and across the channel, it is measured in several manners for different uses. Some of these measures include bulk, mid-channel, inlet, etc.

liall Field - The electric field that is parallel to the direction of gas flow and/or perpendicular to the direction of induced electromotive force (emf). i $X$. In solid state physics, the Hall field is generally defined as the field perpendicular to the direction of current flowi however; this is not used in MHD because the direction of current flow varies with the types of generator and operating conditions.

Hall Current - The electric current flowing parallel to the Hall field.

Häll Generator - A generator hooked up or configured so the Faraday electric field is zero and the power is extracted entirely by means of the $\mathrm{Hall}$ field and $\mathrm{Hall}$ current.
Faraday Field - The electric field perpendicular to the direction of gas flow and/or parallel to the direction of the induced electromotive force (emf). $\overrightarrow{\mathbf{u}} \times \vec{B}$.

Faraday Current - The electric current flowing parallel to the Faraday field.

Faraday Generator - A generator hooked up or configured so the net Hall current is zero and the power is extracted entirely by means of the Faraday field and Faraday current.

Single Circuit Faraday Generator - A generator hooked up or configured so the Hall electric field is zero and the power is extracted entirely by means of the Faraday field and Faraday current.

Diagonal Generator - A generator hooked up or configured so both the Hall and Faraday fields and currents are used to extract power.

Instability - In MHD this is a hot spot or high, local electrical conductivity created by spontaneous field or current concentrations. This phenomena is most of ten encountered in generators employing nonequilibrium ionization or in any type of generator in the immediate vicinity of the electrodes.

Arc Mode - An electrode operating condition in which the current enters or leaves through one or several arcs.

Diffuse Hode - An electrode operating condition in which the current is spread more or less uniformly over the surface of the electrode.

Leakage Current - A current that partially shorts out the generator by flowing in an axial direction along the surface of the generator walls.

Hall Leakage - Same as leakage current.

Slag Leakage - Same as leakage current.

Leakage Resistance - The apparent resistance of the generator's duct to the flow of leakage current.

Boundary Layer Voltage Drop - On a plot of voltage across the duct from anode to cathode wall, boundary layer voltage drop is the difference between the voltage measured at the wall and a line drawn tangent to the plot at the centerline and extrapolated to the wall. Not all of this voltage drop represents a loss. See Figure 2.

Lorentz Force - The force experienced by a current -carrying conductor in a magnetic field; equal to $\overrightarrow{\mathrm{J}} \times \mathbf{B}$.

Generalized Ohm's Lay - The equation for a conductor that relates current to voltage that is generalized to include terms for the Hall effect and for other effects that are significant in certain places (for example very near a wall) in MHD power generation.

Joule Heating - The heating of the working fluid due to current flow. Joule heating is equal to $\mathrm{j}^{2} / 0$ (power density). 


\subsection{POLARIZATION EFFECTS}

The root cause of polarization is common to all MHD generators, but the effects are most dramatic for coal-fired, cold-wall. slagged channels, which is the type of design currently being considered for commercialization. Polarization is related to both power-loss mechanisms and channel electrochemical erosion mechanisms. There is significant effort to determine the causes of polarization and to find methods to eliminate those causes or reduces the effects.

Polarization - A channel phenomenon in which the electric fields drive the positive ions to the cathode wall and the negative ions and electrons to the anode wall. This causes a difference in the electrochemistry of the walls. In particular. metallic ions recombine with electrons at the cathode wall. which allows electrically conductive metal to be deposited there.

Cathode Hall Shorting - A channel phenomenon in which the metal deposited by polarization bridges individual electrode insulators and tends to electrically short out groups of cathode wall electrodes.

Shorted Group - An adjacent group of cathodes that are at the same electrical potential due to cathode wall shorting.

Open Gap - A high voltage that appears between two adjacent cathodes that are part of separate shorted groups.

Desegmentation - A channel phenomenon in which the apparent number of electrically isolated channel frames appears to decrease due to cathode wall shorting.

Resegmentation - A channel phenomenon in which the apparent number of electrically isolated channel frames appears to increase due to a change in the operating condition or the addition of a material used to alter slag electrochemistry.

Current Constriction Hodel - A model for the existence of open gaps, which proposes that high levels of transverse current flow cause Joule heating sufficlent to break down the slag.

Current Reversal Model - A model for the existence of open gaps that proposes reverse current flow at the upstream end of a shorted group depolarizes the slag and causes it to have higher reststance, and therefore. a larger voltage drop.

Axtal Current and/or Arc Model - A model for the existence of open gaps that proposes high current levels in the axial direction along the channel wall will break down the potassium metal bridges and cause an arc to occur, which is sustained by axial current flow along the wall.

Iron Oxide - An additive to the plasma stream, either as a dry powder or in a slurry with a heavy oil, which changes slag electrochemistry and decreases cathode wall shorting.

\subsection{FACTORS AND PARAMETERS}

Below are those quantities that are either completely unique to the field of $\mathrm{MHD}$, are modified from their typical usage, or are generally unfamiliar terms that surface frequently when discussing MHD.

The following list defines symbols that are used in the MHD-associated equations found in this paper.

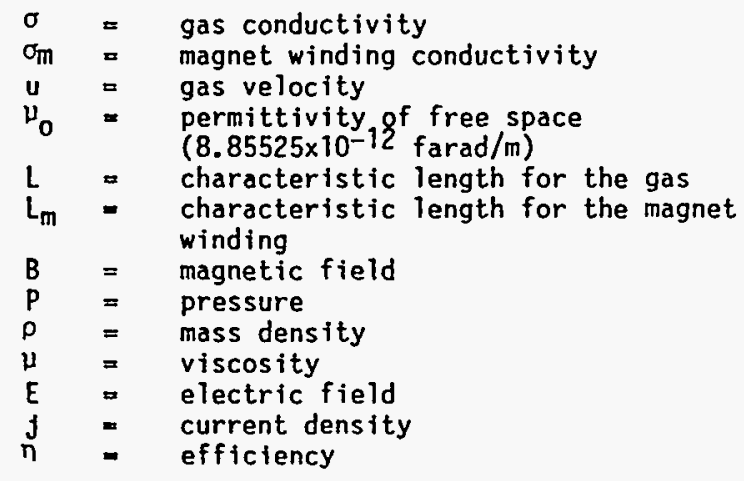

Load Factor ( $k$ ) - The ratio of the load impedance to the sum of the generator and load impedance, $k=R I /(R 1+R g)$. For a short circuit $k=0$, and for an open circuit $k=1$. Also, $k=E y / u B$, where $k$ varies between 0 and 1 for a generator and is greater than 1 for an accelerator.

Loading Parameter - Same as load factor.

G-factor - A parameter used to express the effect of gasdynamic nonuniformity on generator performance. For example, $G=1$ represents uniform gasdynamic properties, and $G=1.5$ means performance is cut by approximately one-third.

Reynolds Number. Magnetic - Approximately equal to the ratio of the induced to the applied magnetic field. This is closely related to the concepts of skin depth and armature reaction.

$$
R_{m}=\mu_{0} \sigma u L
$$

Reynoids Humber. Hixed Magnetic - Approximately equal to the ratio of the power generated by the gas to the power lost generating the magnetic field. If the magnet is superconducting, this is effectively equal to infinity.

$$
R_{m x}=\mu_{0} u \sqrt{\sigma \sigma_{m} L L_{m}}
$$

Hall Parameter - The tangent of the angle between the electric field relative to the flowing gas and the direction of current flow. This is also the cyclotron frequency for electrons times the mean time between collisions for electrons.

Ion Slip - Motion of the positive ions relative to the rest of the gas. This is significant only when the Hall parameter is much larger than any value presently contemplated for use in an MHD generator. 
Hartmann Number (Ha) - A measure of the relative strength of MHD and viscous forces. This number has a bearing on the thickness of the boundary layer formed on the insulator wall of an MHD generator.

$$
H a=B L \sqrt{\frac{\sigma}{\mu}}
$$

\subsection{EQUILIBRIUM/HONEQUILIBRIUA}

Equilibrium, as used here, refers to a condition where the electron and the heavy-particle temperatures are the same. Generators being considered for commercial application typically are in equilibrium.

Equilibrium Generator - A generator operating with plasma in which the electron temperature and heavy particle temperature are equal. All combustion gas driven generators are equilibrium generators, except in regions of strong gradients such as those found near walls.

Nonequilibrium Generator - A generator operating with plasma in which electron temperature is elevated. Noble gas driven generators are usually nonequilibrium generators.

Nonequilibrium Ionization - A method of turning the gas into an electrical conductor by external. nonthermal means, for example, by applying a strong electric field or any of several kinds of energetic radiation. Most often the induced electromotive force (emf), $\vec{u} \times \vec{B}$, is used, the cycle is closed, and an inert gas such as helium is employed.

Fully Ionized Seed - A method for stabilizing the degree of nonequilibrium ionization by using a seed concentration so low that it becomes fully ionized.

Two-temperature Model - A method for predicting the degree of nonequilibrium ionization that will be obtained in a given situation.

\subsection{SPATIAL ORIENTATIOH COHVEHTIOHS}

Figure 3 shows the relationship of spatial orientation conventions (transverse, axial, normal) to the generator configuration.

Transverse Current - Typically the same as Faraday current. The current flow that is at right angles to both the magnetic field and the plasma velocity.

Transverse Voltage - Typically the same as Faraday voltage. It is voltage from a cathode to the anode directly across the channel and which is at right angles to both the magnetic field and plasma flow.

Axial Current - Typically the same as Hall current. The current flow along the length of the channel, in the direction of plasma flow.

Axial Voltage - Typically the same as Hall voltage. This is voltage built up along the length of the channel, in the direction of plasma flow.

Mormal Current - Same as transverse current.

Normal Voltage - Same as transverse voltage.

\subsection{APPLICATIONS TO CONERCIAL POMER GENERATIOH}

In this section, an attempt was made to include terms oriented toward the efforts of achieving MHD commercialization. Terms are subgrouped to gather those used to describe particular phenomenon or that share other characteristics. These groups start with systems terminology, followed by a grouping for topping cycle, and then bottoming cycle. The following groups address seed, magnets, and coal, with combustor technology, channel technology, and electrical technology concluding this section.

\subsection{SYSTEHS TERAIHOLOGY}

Concepts in this section relate to commercial power generating plants as whole entities. Three subgroups appear in this section. The first describes how an MHD topping cycle might be applied to an existing power plant, and how that power plant might be configured and operated. The second subgroup defines efficiencies related to generation plants. For plant and cycle efficiencies, two definitions are provided: 1) a general definition and 2) a more specific definition for combinedcycle plants. The third subgroup deals with environmental effects and how MHD can mitigate them.

\subsubsection{Generating Plants}

Retrofit - The application of an MHD generating cycle to an existing power plant to increase its efficiency and electrical power production capacity.

Gas Side Retrofit - The application of an MHD topping cycle to an existing power boiler replacing some or all of the existing burners. Currently. this method is not favored because of heat transfer surface fouling. See figure 4.

Steam Side Retrofit - The application of an MHD topping cycle with a new boiler designed for MHD service. The connection to an existing plant is through a steam line and using the existing turbine/generator, condenser, etc. Currently, this is the preferred method because it permits design of heat transfer surfaces to counter extensive fouling. See Figure 5 .

MLID Stean Combined Cycle Power Plant - A power plant in which power is generated by both direct conversion in an MHD generator (topping cycle) and by raising steam and using a turbogenerator (bottoming cycle). The MHD topping cycle operates in the highest temperature regimes (roughly 3000$2200 \mathrm{k}$ ) and exhausts to the boiler of the steam bottoming plant.

Emergency Generator - An MHD generator designed for ultra-fast startup and used in a power grid for stabilization in an emergency or for peaking power.

\subsubsection{Efficiency}

Plant Efficiency (general) - The electrical power output divided by the thermal power input.

Plant Efficiency (retrofit) - The total net power generation divided by the total fuel input for both 
plants (topping and bottoming, or retrofit and existing). Net power generation is defined as gross electrical output from the MHD channel and the turbine generator minus the total auxiliary power requirements for both plants. Total fuel input is defined as the thermal input for both the MHD channel and the existing boiler plus the thermal input for coal drying.

Overall Efficiency - Same as plant efficiency.

MHD Cycle Efficiency (general) - The electrical power output from the MHD topping cycle divided by the thermal power input.

Mio Cycle Effictency (retrofit) - The efficiency of the MHO retrofit plant on a stand alone basis. Cycle efficiency is estimated by dividing the total MHD net electrical output by the thermal input to the combustor plus the thermal input for coal drying. Total MHD net electrical output is defined as the gross MHD channel electrical output plus the total electrical output of the HRSR boller system minus the total auxiliary power requirements for the MHD retrofit plant.

Electrical Efficiency (n electrical) - The electric power delivered to the external circuit divided by the total power electromagnetically extracted from the gas stream. For example, if 10 percent of the energy extracted is lost back to Joule heating of the gas, the electrical efficiency would be equal to 0.9 (90\%). Electrical efficiency can be local or global. Equations for these are given below.

$$
\begin{aligned}
\eta_{\text {local eloctrieal }} & =\frac{\vec{E} \cdot \vec{j}}{\vec{u} \cdot(\vec{j} \times \vec{B})}=\frac{\vec{E} \cdot \vec{j}}{\vec{E} \cdot \vec{j}+\vec{j} / \sigma} \\
\eta_{\text {global electrical }} & =\iiint_{v 0 !} \eta_{\text {local oloctrieal }} d u
\end{aligned}
$$

\subsubsection{Environmental Effects}

HOx Thermal Decomposition - The decomposition of nitrogen oxide into nonpolluting compounds and elements as it cools in the radiant furnace (boiler). This thermal decomposition mechanism is the basis of the NOx control system for the MHD Steam Combined Cycle power plant. Decomposition is more rapid at higher temperatures and lower stotchlometry (more fuel rich).

$\mathrm{K}_{2} / \mathrm{S}$ Ratio - The stoichiometric ratio of potassium to sulfur to form potassium sulfate $\left(\mathrm{K}_{2} \mathrm{SO}_{4}\right)$. Operation at $K_{2} / S$ of 1.0 or larger is needed to meet the New Source Performance Standards (NSPS) for sulfur dioxide emissions for Illinois $\$ 6$ coal. Operation at higher $\mathrm{K}_{2} / \mathrm{S}$ ratios produces significant quantities of potassium carbonate $\left(\mathrm{K}_{2} \mathrm{CO}_{3}\right)$, which changes the nature of solids deposition in the bottoming cycle for the worse.

\subsection{TOPPIHG CYCLE}

This section combines terms directly related to the MHD portion of the combined cycle. including hardware and processes. Although they are topping cycle components, the combustor, channel, and magnet are major items; therefore, they are discussed within their own individual sections.

Topping Cycle - The MHD portion of a combined cycle power plant, including combustor, nozzle, channel, magnet, and diffuser.

Hozzle - A hardware component that directs and accelerates the gas entering the generator providing the proper velocity.

Diffuser - A hardware component downstream from the generator that provides expansion and pressure recovery by increasing volume. This slows the gas stream and provides an interface to downstream components.

Air Separation - The production of oxygen by separating it from the other gaseous species in air. For MHD purposes, the most economical system may only increase the concentration of oxygen rather than produce pure oxygen. Air separation may be used as an alternative to preheating air for injection into the MHD combustor.

\subsection{BOTTOHING CYCLE}

The bottoming cycle is also referred to as the conventional cycle because the associated principles are the same as for existing thermal power generating stations. However, the chemistry of the combustion gases in a combined-cycle plant are substantially different than for existing plants and require innovative technology. Additionally, seed recovery and oxygen separation. when used, are functions not currently associated with conventional plants.

Steam Bottoming Plant - The portion of the MHD steam combined cycle plant that accepts hot MHD exhaust gas and generates power by raising steam and passing it through a turbogenerator. The steam bottoming plant also functions to heat air for the topping cycle combustor, may provide steam to drive the combustion air compressor and/or oxygen separation plant, may accept unburned hydrocarbons from the seed regeneration plant, may provide steam to the seed regeneration plant, and may provide heated air or other gases to the coal dryer. See Figure 6.

Heat-Recovery Seed-Recovery (HRSR) System - The system that recovers the heat and spent seed in the gas stream from the topping cycle. The HRSR system includes the boiler, superheater, reheater, air preheater, and all seed recovery equipment.

Intermediate Temperature Air Heater (ITAH) - A recuperative air heater that heats combustion air to around $922 \mathrm{~K}\left(1200^{\circ} \mathrm{F}\right)$ using the heat of the combustion products between the secondary combustor and the superheater. See Figure 6.

Superheater - A heat exchanger that takes the saturated steam from the boiler and raises the temperature above the saturation temperatures, using combustion products as a heat source. It performs the same function as a superheater in a conventional fossil-fueled plant. See Figure 6 .

Reheater - A heat exchanger that accepts the intermediate pressure steam that is approaching 
saturation temperature and raises its temperature, using the combustion products as a heat source. It performs the same function as a reheater in a conventional fossil-fueled plant.

Hot Side Electrostatic Precipitator (ESP) - An electrostatic precipitator (ESP) that operates at a temperature (approx. $700^{\circ} \mathrm{F}$ ) between the superheater/reheater gas temperatures and the low temperature heat exchange surface (economizers, low temperature air heater, coal drying gas heater). The advantage of operating the ESP at an elevated temperature is to remove most of the particulate (spent seed and flyash) before it reaches the low temperature heat transfer components, and thus reducing the heat transfer surface required. See Figure 6 .

\subsection{SEED}

Combustion products by themselves do not have sufficient conductivity to produce commercially economical MHO power. Therefore, an easily ionizable compound must be added. This material should be relatively inexpensive, readily available, recoverable, and reusable. It must produce large increases in conductivity with small additions, and it must also be environmentally benign. In practice, potassium salts are usually used because they meet the above requirements and have the added advantage of removing sulfur from the stack gases by combining with it to form a solid precipitate.

Seed - An easily ionizable substance that is added to the conbustor and dissociates to form positive ions and free electrons, which enhance the conductivity of the MHD plasma. In practice, this is usually a potassium compound such as potassium carbonate $\left(\mathrm{K}_{2} \mathrm{CO}_{3}\right)$. The quantity of seed added to the combustor is specified as the amount of potassium metal added as a weight percent of the total mass flow through the combustor -- this is the percent seed or ZK.

Seed Recovery - The process of recovering seed from slag and fly ash. Primary means of recovery are through the particulate removal system (baghouse or electrostatic precipitator), from convective heat transfer surfaces, and from the slag rejected in the downstream boiler. Seed is in the form of potassium compounds mixed and sometimes chemically bound with coal slag compounds. Seed recovery is also used as the percent of seed recovered as compared to the seed injected.

Seed Regeneration - The conversion of spent seed (normaliy potassium sulfate or a mixture of potassium sulfate and potassium carbonate) back into a chemical form that does not contain sulfur (e.g., potassium carbonate, potassium formate).

Seed/Slag Interaction - The phenomenon in which potassium seed reacts with coal slag and forms a compound normally not soluble in water.

Slag Leaching - The recovery of potassium, which is chemically bound to the constituents in coal slag, by washing with acid or alkaline compounds.

Recycle Ratio $(r)$ - The fraction of an impurity that is recycled in seed regeneration.

Buildup Factor (BF) - Concentration of an impurity at the nth cycle in the MHD seed loop divided by one minus the concentration at the beginning:

$$
B F=\left(1-r^{n}\right) /(1-r)
$$

where: $n$ is the number of cycles. When $n$ approaches infinity:

$$
B F=1 /(1-r)
$$

\subsection{MAGNETS}

For the MHD process. plasma must be passed through a magnetic field (B field). To obtain commercially viable levels of electrical energy. powerful magnetic fields on the order of 2 to 6 Tesla $(20,000$ to 60,000 Gauss) are required. By comparison, at the surface. the earth's magnetic field is approximately 0.5 Gauss.

Conventional Magnet - A magnet that has resistive windings and is generally iron core. This type of magnet is not favored for commercial MHD because the power required to produce the magnetic field is large.

Superconducting Magnet - A magnet with windings that are superconducting. The power required to maintain a magnetic field in a superconducting magnet is very low, making it practical for commercial application. All existing superconducting magnets require supercooled windings, such as with liquid helium.

Superconducting magnets are generally air core.

Iron Core Magnet - A magnet wound around an iron core.

Air Core Magnet - A magnet wound around an air core.

\section{$2.6 \mathrm{COAL}$}

The MHD Program in the United States is based on coal as the energy source. This was chosen because coal is a plentiful fuel source that is relatively inexpensive. In all likelihood, the first commercial usage of MHD will be as a topping-cycle retrofit to an existing coal-fired power plant. The MHD process enhances conventional coal-fired plants because 1) they can continue to be used, 2) their output is increased, and 3 ) harmful environmental effects are minimized. Definitions for HHV and LHV are familiar to general industry use and are only given here to help clarify application. In the United States, common practice is to use the HHV when calculating overall plant efficiency, while in Europe and Russia the LHV is used. The overall plant efficiency number for the same plant may be one-two percent higher when the LHV is used.

Higher Heating Value (HHV) - The energy that must be removed from the calorimeter after combustion of a fuel to return the temperature to $25^{\circ} \mathrm{C}(77 \mathrm{~K})$ and the pressure to one atmosphere, if all the water formed is in the liquid phase.

Lower Heating Value (LHV) - Same as for higher heating value except that all the water-formed is in the vapor phase. 
Tro-phase Flow - Pneumatic transport that is used for transporting coal and seed to the combustor. The dried, powdered material is carried on a moving stream of dry nitrogen gas. Two-phase refers to the solid coal or seed and carrier behaving as one fluid.

Hestern Coal - Coal mined in the Western United States. In general, these are low-sulfur, highmoisture, subbituminous, moderate BTU, high-ash coals.

Rosebud Seam Coal - An example of a Western coal, mined in eastern Montana from the Rosebud coal seam. This is one reference coal around which the United States has standardized its MHD program.

Eastern Coal - Coal mined in the Eastern United States. In general, these coals are high-sulfur, low-moisture, bituminous, high-BTU, and low-ash.

Illinois Number Six (\$6) Coal - An example of an Eastern Coal. This is one reference coal around which the United States has standardized its MHD program.

\subsection{COHBUSTOR TECHIOLOGY}

One of the most critical MHD hardware items is the combustor which takes the varfous inputs (coal, air, seed, etc.) and produces the electrically conductive plasma stream while rejecting excess slag. Designs for commercial-type combustors are expected to operate at four to six atmospheres pressure, about 3000$5000^{\circ} \mathrm{F}$, and several thousand to several tens of thousand volts from ground. The term combustor is frequently used in two manners; it can mean only the main burning chamber or it may include the entire collection of hardware associated with the combustion process.

The combustor can fire coal, oil, natural gas or a combination of these fuels. Much of the work on gasand oil-fired MHD combustors (as well as work on coaloil mixtures) has been done outside the United States. In the United States, combustor development has focused on coal-fired equipment. Recent emphas is has been on slagging combustors, which are designed to reject a portion of the coal mineral matter from the working fluid as slag before it enters the MHD channel.

The terminology related to MHO combustors breaks down into hardware-related terms, operating variables, performance parameters, and combustion efficiency analysis. Definitions for terms used in these four areas are presented below.

\subsubsection{Hardware-Related Terms}

Vitiator - A piece of development hardware used to preheat the oxidizer stream to the combustor first stage. In a commercial MHO plant, oxidizer is assumed to be preheated before being injected into the combustor. During development and proof-of-concept testing, this preheat is obtained by burning fuel oil and pure oxygen directly into the oxidizer stream before feeding it to the combustor. This component would not be part of a commercial plant.

Precombustor - A piece of hardware that takes preheated oxidizer from the vitiator (or air preheater) and a portion of the coal for the process and burns them to further preheat the oxidizer before it enters the combustor first stage.

Combustor - A piece of hardware that generates the electrically conductive plasma required in the generator. It may be single- or multi-stage (most designs for comercial scale combustors are multistage).

First Stage - The first stage of a multi-stage combustor. Coal is burned substoichiometrically (with less then the amount of oxygen needed for complete combustion) to achieve the required slagging conditions at low heat loss and to produce a combustible fuel-rich gas stream that is fed to the second stage.

Second Stage - The second stage of a muiti-stage combustor where additional oxidizer is injected to complete (or nearly complete) fuel combustion.

Air Preheater - A heat exchanger used to preheat the combustor oxidizer by indirect heat exchange with hot product gases from the combustion process. In a commercial MHD plant, this heat exchanger is called the air preheater.

Ash Injection - Fly ash used with oil-fired combustors to simulate the slag carried over to the channel and downstream components of the process when coal-fired combustors are used. An oil-fired ash-injected combustor is often referred to as an AIC.

Coal-fired - Refers to the fuel used for combustion, as in coal-fired precombustor (CFPC) or coal-fired combustor (CFC).

0i1-fired - Refers to the fuel used for combustion. as in oil-fired vitiator (OFV) or oil-fired combustor (OFC).

Slagging - The process of separating some of the mineral matter in the fuel from the combustible portion as molten slag. Slag coats the walls of the combustion chamber and may be removed before it enters the downstream section of the power train.

Continuous Slag Rejector - A slag removal system attached to a combustor that is designed to provide continuous slag removal capability (as opposed to using a batch-mode slag dump tank, which limits run time unless it can be emptied on-line).

Horkhorse Design - Hardware that features waterwall construction and is of modular design, allowing flexibility of configuration. This type of construction is generally not applicable to operation with high-pressure, high-temperature boiler feedwater.

Prototypical Design - Hardware designed to have features similar to the equipment that would be used in the first MHD power plant retrofit. It is cooled by high-temperature, high-pressure water and is designed to run for long durations.

\subsubsection{Operating Variables}

Stoichiometry - When the necessary oxygen required to burn all of the available fuel is provided, with no oxygen or fuel left over. 
Equivalence Ratio - The equivalence ratio (phi or $\emptyset$ ) is the ratio defined by the amount of oxygen (on a mass or molar basis) fed to the combustor divided by the theoretical amount of oxygen (on the same mass or molar basis) required for complete combustion:

$$
\emptyset=\frac{0_{2} \text { available }}{0_{2} \text { necessary for stoichiometry }}
$$

Therefore, when $\emptyset=1.0$, conditions are

stoichiometric. For equivalence ratio, all sources of oxygen in the feed streams are considered. including oxygen in the coal and seed. (Hote: Some authorities refer to the above definition as stoichiometric ratio and define equivalence ratio as the reciprocal of stoichiometric ratio). For a twostage combustor with a coal-fired precombustor, three equivalence ratios are defined: 1) the precombustor equivalence ratio (phi 01), which includes only oxygen inputs to the precombustor combustion chamber, 2) the first-stage equivalence ratio (phi 1), which includes only oxygen inputs to the first stage, and 3 ) the overall (or global) equivalence ratio (phi 2), which includes all oxygen inputs. The following ranges are typical for the three equivalence ratios: (phi 01) = 0.65 to 1.2 , (phi 1) $=0.5$ to 0.7 . (phi 2) $=0.8$ to 1.05 .

N/0 Ratio - The molar ratio of nitrogen to oxygen in the combustor feed streams is called the $N / O$ ratio. It is generally specified as an overall (or global) ratio, which accounts for all of the nitrogen and oxygen in all feed streams (including carrier gases for solids transport).

Thermal Rating - The thermal rating (or thermal throughput) of a combustor is the heat input rate considering all fuels, including vitiator and precombustor inputs. Higher heating values are used to calculate this rating. which is expressed in megawatts and is abbreviated $M W_{t}$ (the subscript $t$ denoting thermal megawatts).

Total Mass Flow - The sum total of all inputs to the combustor measured in mass per unit time (e.g., $\mathrm{kg} / \mathrm{sec}, 1 \mathrm{bm} / \mathrm{hr}$ ).

\subsubsection{Performance Parameters}

Heat Loss - Heat loss in the combustor is defined as the sensible heat lost to the cooling circuits, and it is often stated as a percent of the total thermal throughput. Heat flux, defined as the heat loss per unit area for a component, is also used -particularly for specific combustor components. Typical values for relative heat loss in a 50- $\mathrm{HW}_{\mathrm{t}}$. multi-stage combustor are as follows: precombustor about 1 percent, first stage about 5-6 percent. second stage (excluding nozzle) about 2 percent. Heat fluxes for individual first-stage components (at steady state) range up to about $100 \mathrm{Btu} / \mathrm{s}-\mathrm{ft}^{2}$ (heat fluxes in the second stage can exceed this value).

Slag Recovery - Slag recovery is defined as the dry weight of slag removed from a combustor first stage as a percentage of the weight of $\mathrm{SO}_{3}$-free ash fed to the combustor. (Since $\mathrm{SO}_{3}$ is volatile, it is not found in the collected slag.) Slag recoveries generally range from 40 to 80 percent.

\subsubsection{Combustion Efficiency Analysis}

Carbon Closure - The mass of carbon out of the test train divided by the mass of carbon into the test train (usually expressed as a percentage). A carbon closure of 1.0 would indicate a perfect carbon balance.

Carbon Balance - The calculations necessary to determine carbon closure.

Het Gas Analysis - The analysis of combustion offgases including moisture. In this type of analysis, the gas is heated to keep the motsture in a vapor phase.

Dry Gas Analysis - The moisture-free analysis of combustion off-gases. In this type of analysis, the gas is chilled below the dew point for moisture removal and dried further by desiccants. Since the total volume of the off-gas is not analyzed, measurements for stack gas velocity, temperature, and pressure are needed to calculate moisture and total volume.

Hass Balance Closure - The total mass out of the test train divided by the total mass into the test train (usually expressed as a percentage). A mass balance closure of 1.0 would indicate a perfect mass balance.

Haterial Balance Closure - Same as mass balance closure.

Hass Balance Ratio - For a given tfme interval and spatial unit, the mass balance ratio is the sum of mass outputs plus the final internal mass in the spatial unit divided by the mass inputs plus the initial internal mass in the spatial unit (all massec expressed in the same units). The mass ratio may be expressed as a percent or as a unit less ratio, and when applied to elements, total mass, or unchanging compounds, the mass ratio is ideally one.

\subsection{CHANHEL TECHHOLOGY}

The channel is an important link in the MHD process; the high-temperature, high-velocity plasma must be contained and the electrical energy tapped. The channel must resist electrochemical corrosion for thousands of hours, but not be prohibitively expensive. The ongoing search for such a unit is the driving force behind materials studies. This section has two subgroups; the first discusses the unique nomenclature associated with channeis and the second addresses the materials and processes used for building channels.

\subsubsection{Nomenclature}

Channel - A linear MHD generator. Typically channels are rectangular in cross-section and diverge from inlet to outlet. The divergence is usually not the same from side-to-side as from topto-bottom and is designed to maintain a constant velocity of the gas stream along the channel length.

Anode - The electrode that is the electron collector (from the channel internal point of view). This makes the anode negative with respect 
to the same point on the cathode wall. This is atypical for most devices encountered in electrical engineering since the latter most often consumes power rather than generates it and are concerned with an external, not internal, viewpoint.

Cathode - The electrode that is the electron emitter (from an internal point of view). This makes the cathode positive with respect to the same point on the anode wall. This is atypical for most devices encountered in electrical engineering since the latter most often consumes power rather than generates it and are concerned with an external, not internal. viewpoint.

Sidewall - One of the two typically nonemitting or noncollecting walls (except for diagonal conducting wall generators), which are generalily perpendicular to the magnetic field.

Left Sidewall - The sidewall on the left if one takes the position of the plasma stream as it is going down the channel, assuming a heads-up attitude.

Right Sidewall - The sidewall on the right if one takes the position of the plasma stream as it is going down the channel, assuming a heads-up attitude.

Barmall - A sidewall comprised of long rectangular elements oriented at the angle of the equipotential plane in the generator. This orientation reduces the element-to-element voltage stress and is determined by the Hall effect. See Figure 7.

Pegwall - A sidewall comprised of peg elements where each element is a standard size and shape and is typically square, except along the edges of the wall. This design reduces electrochemical corrosion and enhances diagnostic capability by allowing smaller portions of the sidewall to be electrically viewed. Improved electrical isolation between the anode and cathode walls is inherent. This design also allows more part-load flexibility. See Figure 8.

Electrode - An anode or cathode.

Segmented Electrode - An anode or cathode that is not solid but is divided into a number of segments typically individually wired. This individual wiring aids in diagnostics by giving the cross-channel current distribution. See Figure 9.

Peg Electrode - Same as segmented electrode.

Pitch - The distance from a point on an electrode to the same point on an adjacent electrode, either upstream or downstream. This is not the same as the electrode width because it includes the insulator between the electrodes. See Figure 9.

Replenishment - A method for maintaining a good electrode surface by replacing electrode material as fast as it is worn away.

\subsubsection{Materials}

Electrode Material - Electrodes are most commonly made of copper, although ceramics and other materials are used.

Copper Electrode - Copper is used as an electrode material because it has good electrical and thermal conductivities; however, it is highly vulnerable to electrochemical corrosion.

Ceramic Electrodes - Ceramics are used to minimize electrochemical corrosion and to allow the plasma side of the electrode to run hotter, thereby reducing thermal boundary layer losses. However, ceramic electrodes are difficult to fabricate, have poor conductivity, and are subject to thermal shock.

Capping - Covering the face of the electrode with an alternate material for protection from electrochemical corrosion (done especially on copper electrodes). These materials are bonded to the eiectrode by methods such as brazing or explosion bonding.

Tungsten Cap - Typically 25 percent copper and 75 percent tungsten, this material is used because it provides good resistance to electrical arc damage.

Stainless Steel Cap - Typically Type 446 stainless (26 percent $(r)$, this material is used because it provides good resistance to anodic chemical corrosion.

Platinum Cap - Typically pure platinum, this material is used because it provides good resistance to anodic chemical corrosion.

Boron Nitride - An electrical insulator commonly used to provide interelectrode isolation.

Slag Retention Groove - A slot cut into electrodes and sidewall elements so slag is retained on the wall and good slag coverage is obtained.

\subsection{ELECTRICAL TECHNOLOGY}

After the electrical energy arrives at the electrode stud, it must be converted or conditioned into a form suitable for the commercial power grid. This includes conversion from dc to ac power while maximizing power output, protecting the channel from detrimental current concentrations, and providing fault protection for both the ac and dc sides. Ideally, this should be accomplished without incurring any electrical energy losses. There is an interest in using electrical measurements to monitor the internal generator state because direct measurement of velocity, temperature, and pressure are not typically available. This section has three subgroups: the first addresses channel configuration or how the channel electrodes are connected to themselves and the external network, the second addresses hardware and concepts for providing the power conditioning discussed above, and the last details electrical measurements (and related topics) typically made on large-scale MHO generation facilities.

\subsubsection{Channel Electrical Configuration}

Faraday Connection - An electrical connection that relies on only the Faraday field for power production. The connection is made when each cathode is connected through a separate load resistance or inverter to the anode that is directly across the channel from it. Also refer to the explanation for current consolidation. 
Faraday Link - An external connection between an anode-cathode pair, creating a Faraday connection. In generator tests this link is typically resistive but in a commercial generator would contain a small individual inverter or consolidation circuit plus a larger inverter.

Load Profile - The value in ohms of the resistance in each Faraday link plotted against channel position.

Diagonal Connection - An electrical connection that relies on both the Faraday and Hall fields for power production, and is made by connecting each cathode to an anode downstream from it. This connection requires a primary load (e.g.. inverter) to be connected between electrodes at the front and back ends of the channel. See Figure 10.

Diagonal Link - An external connection between an anode-cathode pair, creating a diagonal connection. This link is typically resistive in an experimental situation but would contain a current control circuit in a commercial application.

Link Resistance - The value in ohms of the resistance in a Faraday or diagonal link.

Link Resistor - The physical resistor used as a link resistance. See Figure 10.

Ballast Resistance - Same as link resistance.

Ballast Resistor - Same as link resistor.

Blocking Resistor - Same as link resistor.

Overlap Angle - The distance downstream of the anode with respect to the cathode when making a diagonal connection. This distance can be expressed as an angle in degrees or as the number of channel frames or pitches connected. See Figure 10.

$N+x$ - A method for stating the overlap angle in terms of channel frames or pitches. For example, an $\mathrm{N}+11$ connection means that the cathode at frame 3 would be connected to the anode at frame 14, and so on for the length of the channel. See figure 10.

Power-take-off Region - For a diagonal connection, the end regions of the generator where electrodes are connected to the main load. See figure 10.

Power Generation Region - For a diagonal connection, the center of the channel that is comprised of diagonal links, where voltage and current are built up. See Figure 10.

\subsubsection{Power Conditioning Terminology}

Inverter - The device that converts dc electrical energy from the MHD generator to three-phase ac electricity suitable for the commercial power grid.

Current Controls - Devices placed in the diagonal links of the MHD generator in place of link resistors to keep discontinuities on the cathode wall from.. being reflected onto the anode wall.

Current Averaging - The method by which the current controls operate. Current from a number of adjacent electrode pairs is averaged on a continuous bas is to cancel the effects of localized disturbances.
Current Consolidation - Any number of various methods for combining currents from various powertake-off (PTO) electrodes into one current in a single conductor that serves as the inverter bus. Ideally, this consolidation is done while minimizing the voltage stress on the channel and without dissipating dc electrical energy. Figure 10 shows an example of a current-consolidation network used at the CDIF for testing. Electronic consolidation circuits for commercial application are under development.

Potential Defining Converter - Works in conjunction with current consolidation to minimize voltage stresses.

\subsubsection{Electrical Measurenents}

Interelectrode Voltage - Any voltage between two adjacent anodes or two adjacent cathodes.

Electrode Current - Electrical current from one individual anode or cathode.

Faraday Voltage - Any voltage from a cathode to an anode in the same channel frame.

Hall Voltage - The end-to-end voltage in the direction of the gas stream, along the channel. The Hall voltage is the integral of the Hall field along the generator length.

Combustor Yoltage - When the diffuser is grounded, this is the same as the Hall voltage.

Bus Voltage - The dc voltage at the input to the inverter. (This is the positive bus to negative bus voltage and does not include a ground reference.)

Bus Current - The dc electrical current at the inlet of the inverter on either the positive or negative bus.

Load Voltage - Same as bus voltage.

Laad Current - Same as bus current.

Short Circuit Current - The current that would be obtained by connecting a zero ohm load (short circuit) on the channel. (This is the same as for more typical, nonMHD power sources.)

Open Circuit Voltage - The voltage that would be obtained by connecting an infinitely large load (open circuit) on the channel. (This is the same as for more.typical, nonMHD power sources.)

Load Line - A plot of load voltage versus load current (shown in Figure 11). The curve connects the open-circuit voltage and the short-circuit current. All values of load resistance will generate an operating point along this line, assuming all other operating conditions remain unchanged. The generator maximum load power point will be at one-half the open circuit voltage and the short circuit current (if the line is straight).

V-I Curve - Same as load line. See figure 11. 


\section{CONCLUSION}

This paper is intended to provide a tool for communication within the MHD community. An effort such as this is a difficult first step toward standardizing MHD-unique terminology. Suggestions and comments may be addressed to $A$. T. Hart. Test Engineer, MSE, Inc., P. 0. Box 3767, Butte, MT 59702. If sufficient interest is expressed; updated information will be submitted for future SEAM Conference consideration.

In addition to the Iisted co-authors, many others contributed toward making this document more accurate and more concise. A special thanks to those people.

\section{BIBLIOGRAPHY}

1. Rosa, Richard J.. "Magnetohydrodynamic Energy Conversion". Revised Printing 1987.

2. Sheth, A. C. et al.. "Impact of Impurities on Plasma Conductivity and Available Options for Controlling Their Bufldup". Proceedings of the 23rd SEAM, Somerset, PA, June 1985.

3. Crawford, L. W. et al., "Nitrogen Oxide Control in a Coal Fired MHD System". Proceedings of the 21st SEAM, Argonne, IL, June 1983.

The resources listed above are only a small sample of the MHO literature available. Other sources of information include the Proceedings of the Annual Symposia on the Engineering Aspects of MHD, the Proceedings of the International Conferences on MHD Electric Power Generation, and various reports published by the UTSI, IISE at the CDIF, TRW, and Arco.

\section{ACKMOHLEDEEHENT}

This work was conducted under contract to the United States Department of Energy, Contract Number DE-AC07-881D12735

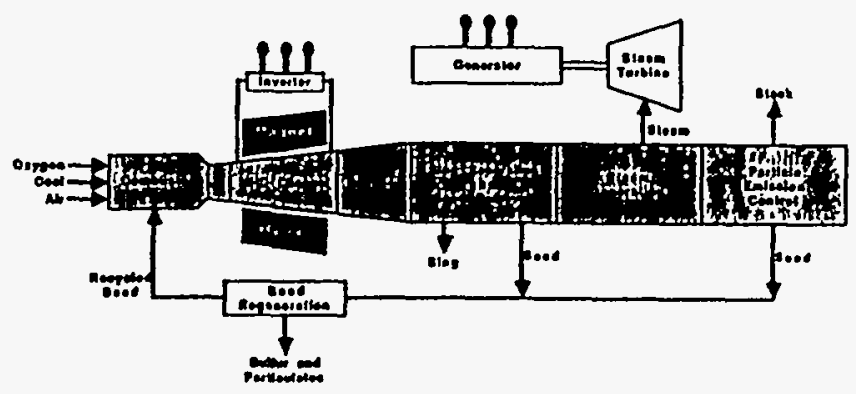

FIOUFE , - TYPICAL OPEN ĊYCLE MOD SYSTEM COMPONENT neruncentert

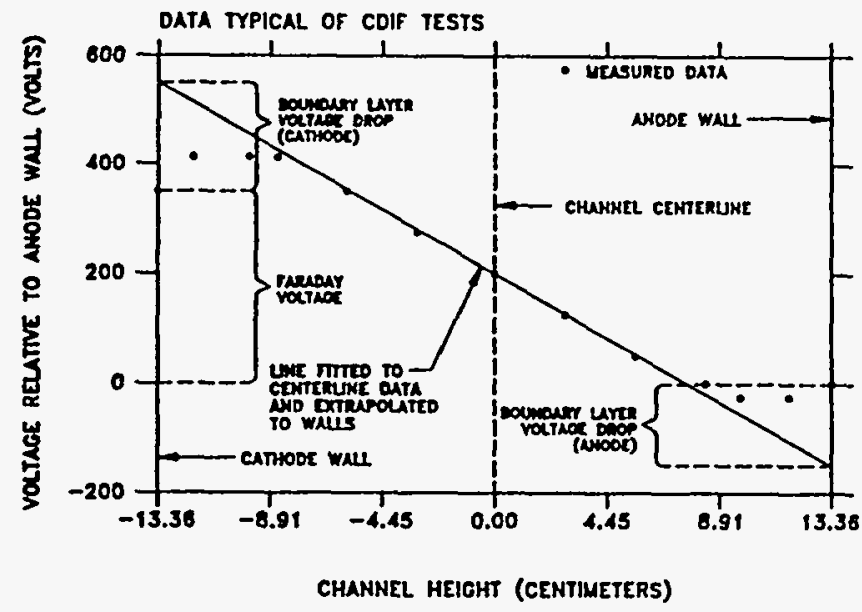

FIGURE 2 - BOUNOARY LAYER VOLTAGE DROP AS INDICATED EY CDIF DATA

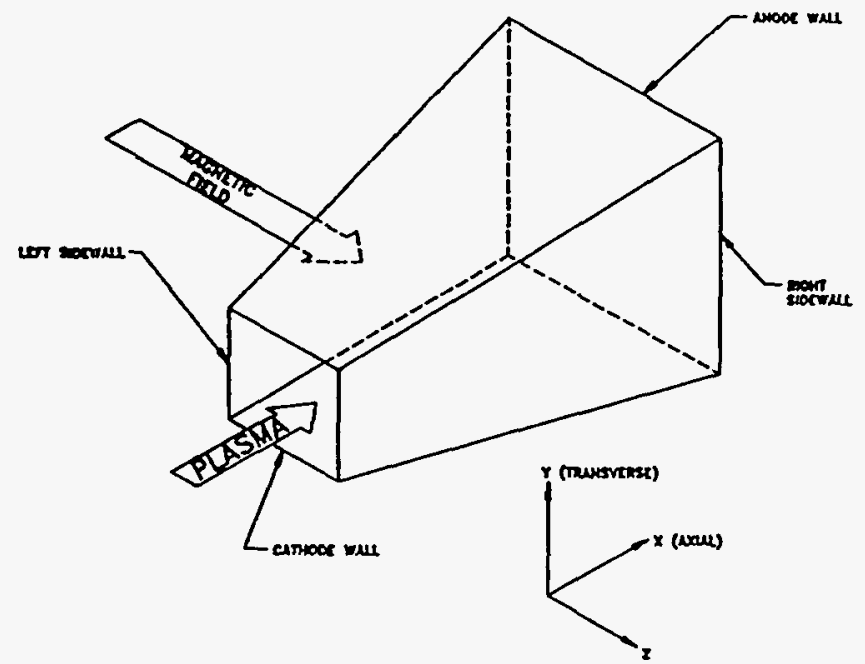

FIQUFE 3 - THE RELATIONSHIP OF SPATIAL ORIENTATION CONVENTIONS TO THE GENERATOR CONF ICURATION 


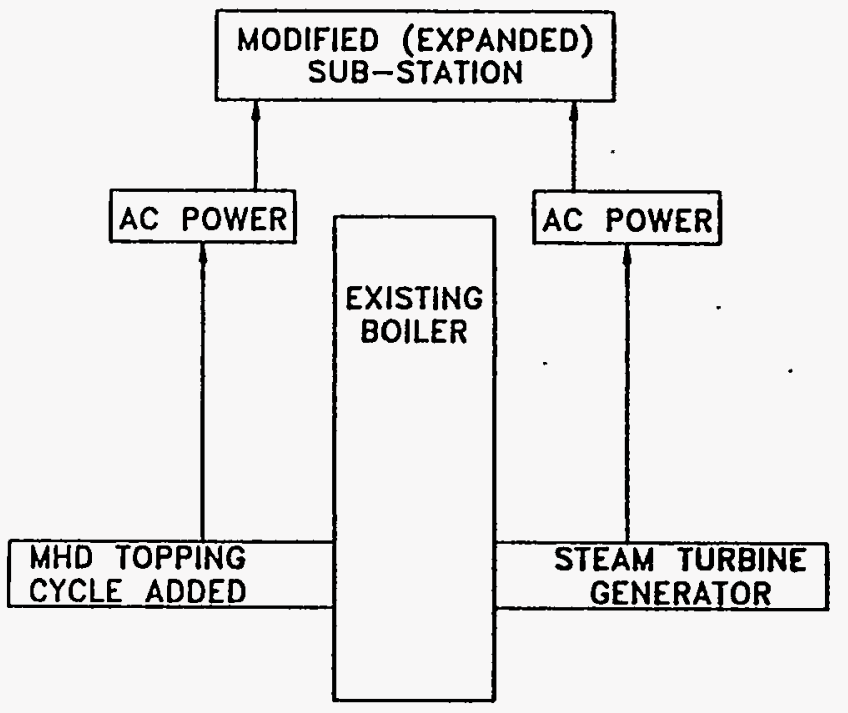

FICURE 4 -. MHD GAS BIDE RETROFIT CONFICURATION

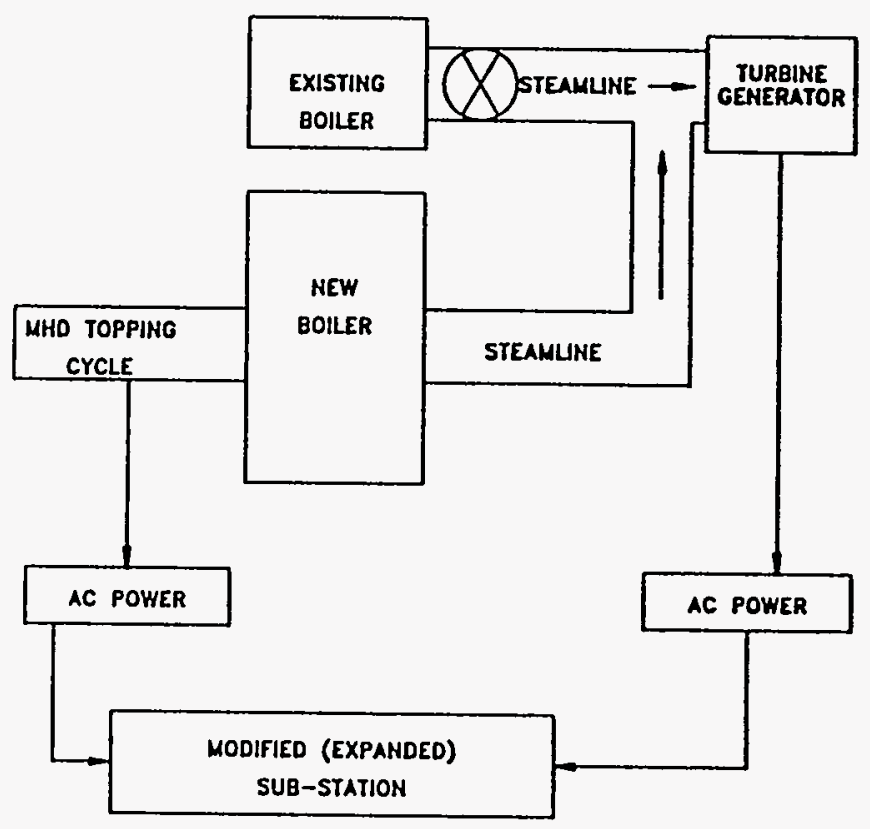

FIGURE S - MHD STEAM SIDE RETROFIT CONFICURATION

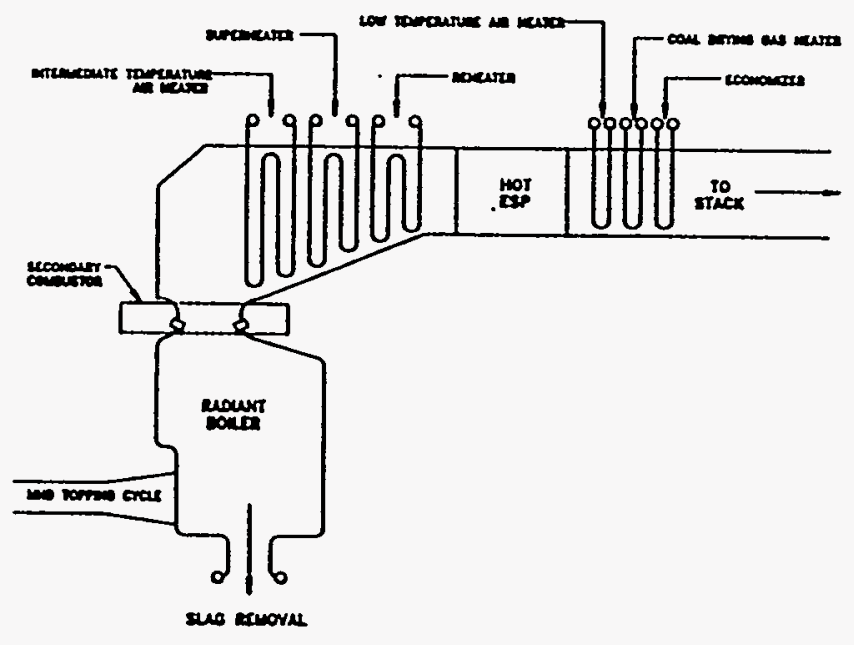

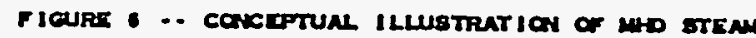
Botraning PLANT

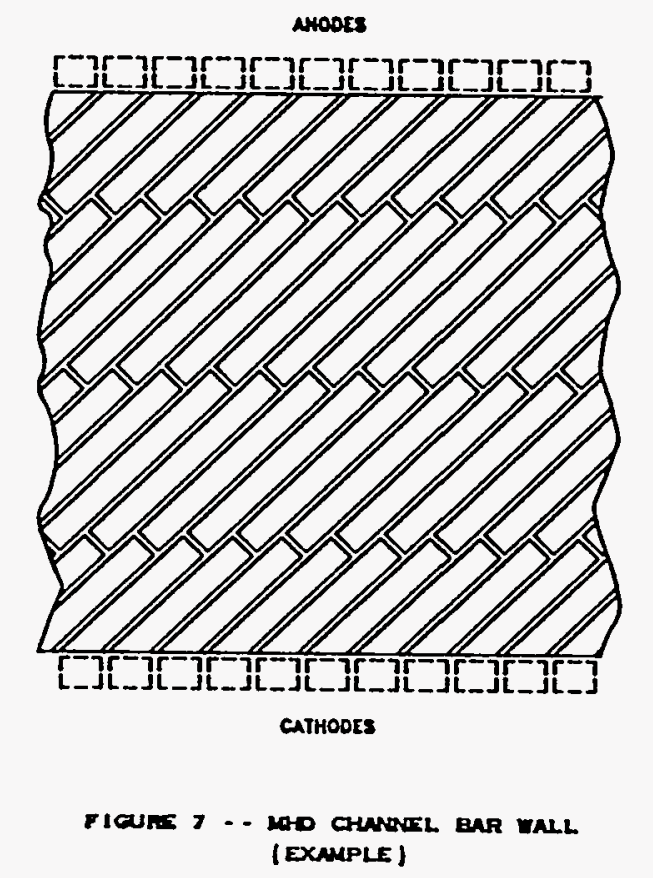




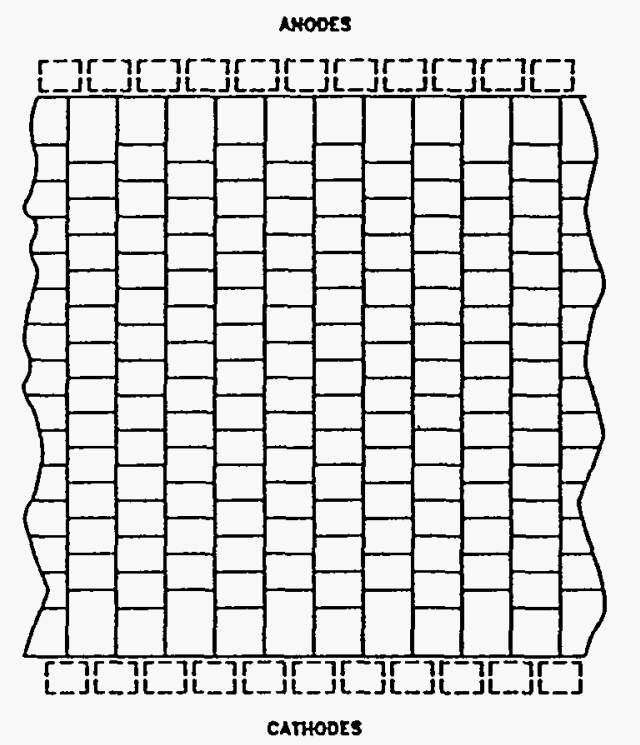

FIGUFE : - MHO CHANEL PEO WALL

(ECAMPLE)

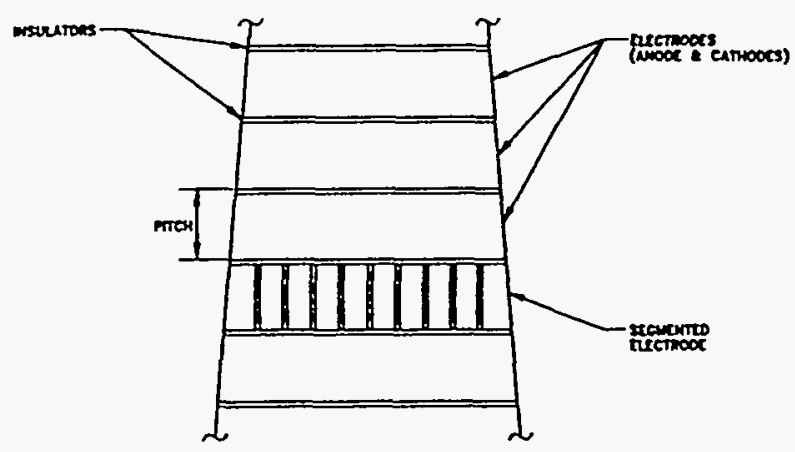

FICUFE, - SEGHENTED ELECTRCOE BET IN MN MOD CHANTEL WALL

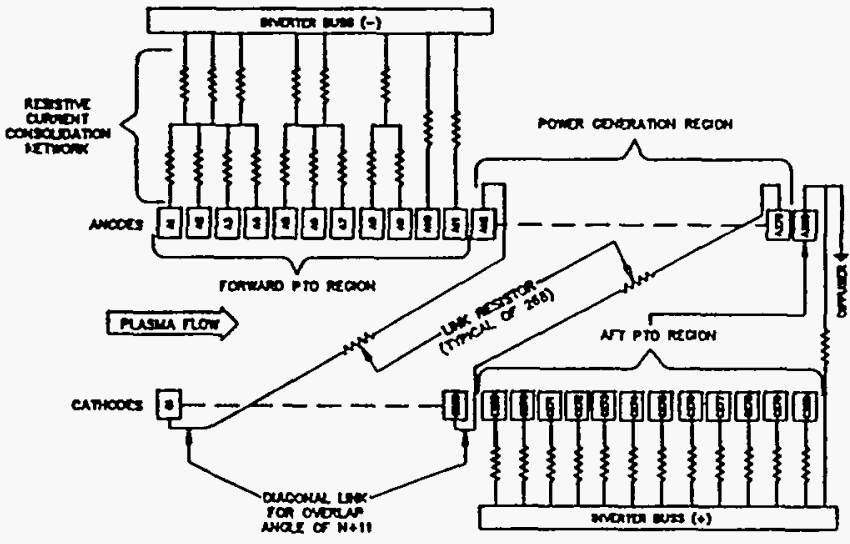

FIOUFE 10 -. TYPICAL, CHANNEL ELECTRICAL CONF IGURATION FOR COIF TESTING

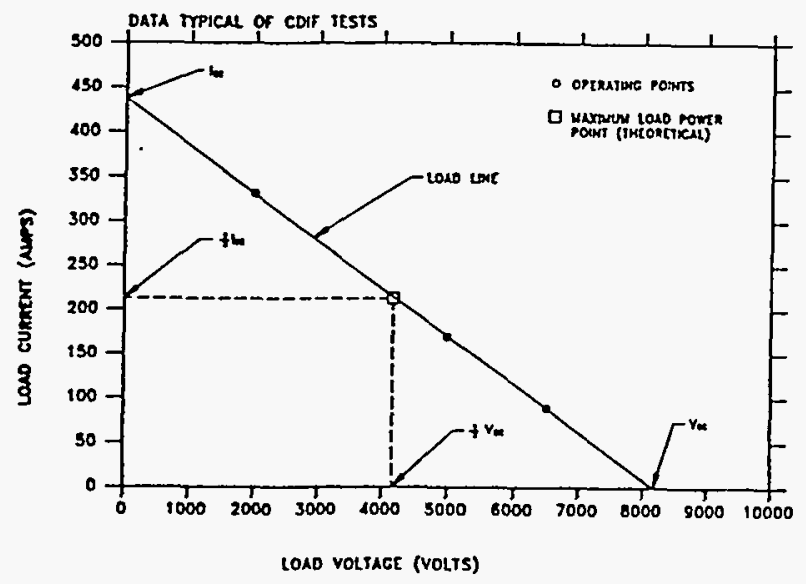

FIQUFE II - LOAO LINE (V-I CUFNE) FROM TYPICAL CDIF DATA 